\title{
EMPLOYMENT FLUCTUATIONS in a DUAL laBOR MABKET
}

James costaim Juan F. Jimeno and Callos Thomas.

Documentos de Trabajo. N. 1013

\section{BANCODEESPANA}

\author{
Eurosistema
}


EMPLOYMENT FLUCTUATIONS IN A DUAL LABOR MARKET

James Costain, Juan F. Jimeno and Carlos Thomas

BANCO DE ESPAÑA

Documentos de Trabajo. N ${ }^{\circ} 1013$ 
The Working Paper Series seeks to disseminate original research in economics and finance. All papers have been anonymously refereed. By publishing these papers, the Banco de España aims to contribute to economic analysis and, in particular, to knowledge of the Spanish economy and its international environment.

The opinions and analyses in the Working Paper Series are the responsibility of the authors and, therefore, do not necessarily coincide with those of the Banco de España or the Eurosystem.

The Banco de España disseminates its main reports and most of its publications via the INTERNET at the following website: http://www.bde.es.

Reproduction for educational and non-commercial purposes is permitted provided that the source is acknowledged.

() BANCO DE ESPAÑA, Madrid, 2010

ISSN: 0213-2710 (print)

ISSN: 1579-8666 (on line)

Depósito legal: M. 19682-2010

Unidad de Publicaciones, Banco de España 


\section{Abstract}

In light of the huge cross-country differences in job losses during the recent crisis, we study how labor market duality - meaning the coexistence of "temporary" contracts with low firing costs and "permanent" contracts with high firing costs - affects labor market volatility. In a model of job creation and destruction based on Mortensen and Pissarides (1994), we show that a labor market with these two contract types is more volatile than an otherwiseidentical economy with a single contract type. Calibrating our model to Spain, we find that unemployment fluctuates $21 \%$ more under duality than it would in a unified economy with the same average firing cost, and $33 \%$ more than it would in a unified economy with the same average unemployment rate.

In our setup, employment grows gradually in booms, due to matching frictions, whereas the onset of a recession causes a burst of firing of "fragile" low-productivity jobs. Unlike permanent jobs, some newly-created temporary jobs are already near the firing margin, which makes temporary jobs more likely to be fragile and means they play a disproportionate role in employment fluctuations. Unifying the labor market makes all jobs behave more like the permanent component of the dual economy, and therefore decreases volatility. Unfortunately, it also raises unemployment; to avoid this, unification must be accompanied by a decrease in the average level of firing costs. Finally, we confirm that factors like unemployment benefits and wage rigidity also have a large, interacting effect on labor market volatility; in particular, higher unemployment benefits increase the impact of duality on volatility.

Keywords: Firing costs, temporary jobs, unemployment volatility, matching model, endogenous separation.

JEL classification: E32, J42, J63, J64, J65. 


\section{Introduction $^{1}$}

The (un)employment response to GDP fluctuations seems to vary significantly across countries and time periods. Looking at the recent experience during the crisis, the change in unemployment for each percentage point fall in GDP ranges from 0.1 in Germany to 2.2 in Spain. ${ }^{2}$ And in contrast with the US, in Europe the impact of GDP fluctuations on unemployment seems to have increased in recent years. For instance, Bertola (2009) shows that in the US, the unemployment rate rose by roughly 0.4 percentage points for each one percent slowdown in GDP growth throughout the 1962-2007 period, whereas in France this ratio rose from 0.14 in 1962-82 to 0.4 in 1983-2007. Furthermore, during the current crisis, the responsiveness of the unemployment rate to the GDP slowdown seems to have been even higher, both for the US and for France.

There are many possible explanations for cross-country differences in unemployment volatility. First, GDP fluctuations may be caused by different types of shocks, in terms of sources (preferences, productivity, etc.) and sectoral composition (more or less concentrated in labor-intensive activities), and the response of unemployment may differ accordingly. Secondly, unemployment fluctuations are conditioned by institutions that constrain labor market flows by creating firing and hiring costs, by wage determination procedures that lead to nominal or real wage rigidities, and also by unemployment benefits and other social policies. In this regard, a major recent institutional change in several European countries has been the liberalization of "atypical" employment contracts (temporary contracts) which have become so prevalent in several countries that the labor market has taken on a dual structure. Also, in fighting the most recent downturn, countries have differed significantly in their employment policy approaches, with Germany emphasizing subsidies to shortterm work schemes while others have substantially expanded income support for job losers and income earners. ${ }^{3}$

This paper focuses on the role of dual labor market institutions in explaining the volatility of (un)employment. Specifically, we analyze the cyclical consequences

\footnotetext{
${ }^{1}$ We thank Laura Hospido and Aitor Lacuesta for providing us with data. We thank Manuel Toledo and seminar participants at Banco de España, the ECB/CEPR conference on "European Labour Market Adjustment", Università di Roma Tor Vergata and the ZEW conference on "Flexibility in Heterogeneous Labor Markets" for helpful comments. The views expressed in this paper are those of the authors and do not necessarily coincide with those of the Banco de España or the Eurosystem.

${ }^{2}$ Babecký, van der Cruijsen-Knoben, and Fahr (2009).

${ }^{3}$ For a summary of the employment policies put in place by OECD countries to deal with the recent economic downturn, see OECD (2009).
} 
of permitting hiring under two different types of employment contracts, temporary and permanent. Temporary contracts have a limited duration, and when they expire the firm must decide whether to keep the worker under a permanent contract or dismiss her at no cost. Permanent contracts are open-ended, but dismissals entail strictly positive firing costs. Under this dual structure, firms face three relevant decisions: i) hirings under each type of contract, ii) upgrading of temporary workers into permanent positions, and iii) firings of permanent and temporary workers. All these decisions are strongly affected by the gap in firing costs between the two types of contracts, and therefore this gap also has a large impact on the response of labor market flows to macroeconomic shocks.

To perform this analysis, we construct a version of the Mortensen-Pissarides (1994) model of endogenous job creation and destruction extended to include: i) two coexisting types of employment contracts, ii) contract-specific hiring and firing behavior, and iii) conversion of temporary employees into permanent ones. Hiring, firing, and conversion are driven both by economic and legal considerations. First, matching frictions constrain job creation; once matches are formed, productivity shocks drive job creation and job destruction. To account for business cycle fluctuations, we assume productivity shocks have an aggregate component; to endogenize separation, we assume they have a match-specific component too. Second, legal constraints on temporary employment are modeled by assuming that temporary contracts expire at a given rate. When a worker's temporary status expires, the firm must either give her permanent status, or fire her.

Within this framework, which assumes flexible wages, hiring and firing decisions depend on the productivity of the match. All new jobs (endogenously) start under temporary contracts; for a match to start, its productivity must exceed a hiring threshold. A temporary match separates whenever its productivity falls below this same threshold. Additionally, in each period, a certain fraction of temporary contracts expire. Of these matches, those with productivity above a conversion threshold are upgraded to permanence, while those with productivity below that threshold are dismissed. Finally, permanent workers are dismissed when the productivity of the match falls below a firing threshold. These three thresholds can be unambiguously ordered: the conversion threshold lies above the hiring threshold which, in turn, lies above the firing threshold. Moreover, the thresholds vary with the state of the economy, and the distance between them depends on the level of firing costs, with all three thresholds collapsing into one if firing costs are nil. This ordering helps us understand both the steady-state and cyclical effects of duality. For instance, the fact that the conversion threshold exceeds the firing threshold has negative productivity consequences, with lower productivity permanent matches kept in place while higher 
productivity temporary matches are destroyed.

To assess the impact of duality on employment volatility, we calibrate the model to Spain - an extreme example of a dual contract environment - choosing parameters to match the average stocks and flows in the Spanish labor market. The model captures the volatility of unemployment and of both job types quite successfully; in particular, temporary employment is more volatile in relative terms (i.e., in terms of its coefficient of variation) than permanent employment. More strikingly, temporary employment also explains a larger part of total employment fluctuations, in spite of the fact that it represents a smaller stock. We then perform simulation exercises to compare the employment volatility in the benchmark dual labor market with that in an alternative policy environment featuring a single employment contract. We consider a wide range of firing costs for the single contract scenario, including (a) setting the firing cost of the single contract equal to the average firing cost in the dual benchmark economy and (b) adjusting the firing cost of the single contract until the steady state unemployment rate equals that in the dual benchmark. In all cases, unemployment is less volatile in the single contract setting than it is in our dual benchmark scenario. The intuition is the following. In booms, a certain fraction of newly-created temporary jobs are "fragile", in the sense that their productivity lies below the firing threshold for recessions. Such fragile jobs are destroyed as soon as the next recession arrives, producing large "spikes" of job destruction. This is not the case for permanent jobs, which are never created at low productivity levels, due to the anticipation of firing costs. In the single contract scenario with firing costs, all jobs behave rather like the permanent component of the dual scenario, which reduces the burst of firing that occurs at the beginning of each recession.

Many papers have explored the macroeconomic implications of dual labor contracting, but most have only addressed steady-state labor market behavior. Blanchard and Landier (2002) model temporary contracts as contracts of limited duration that can be terminated at little or no cost, which become subject to regular firing costs if converted to permanence. They show that introducing such contracts may increase turnover, and thus raise unemployment instead of lowering it. Cahuc and Postel-Vinay (2002) embed this conversion decision into a Mortensen-Pissarides (1994) framework and assume that a constant fraction of new hires must take place under permanent contracts due to legal restrictions. Dolado, Jansen, and Jimeno (2007) is another variant of the Mortensen-Pissarides model that analyzes dual labor markets, focusing instead on the fact that temporary contracts are targeted specifically to low-skilled workers.

There is much less work on the implications of duality for employment volatility; to the best of our knowledge only Sala and Silva (2009) and Sala, Silva, and Toledo 
(2009) have modeled dual labor markets over the business cycle. They conclude that a labor market with dual contracting is an intermediate case, more volatile than an economy with permanent contracts only, but less volatile than one without firing costs. In a similar vein, Cahuc, Le Barbanchon, Bentolila, and Dolado (2009) use this framework to compare employment adjustments in France and Spain during the crisis, but they treat this as a comparison of steady states, instead of calculating the model's dynamics.

Sala et al. (2009) is the paper most closely related to our own, since it studies cyclical dynamics in a model with a similar treatment of endogenous separation and labor market duality. The small but crucial difference in our work is our assumption that both the aggregate and match-specific components of productivity are persistent. Sala et al. (2009) instead assume the match-specific productivity component has no persistence (in other words, it is an i.i.d. shock). This simplifies calculations, by eliminating the need to solve for the equilibrium distribution of productivities. Unfortunately, assuming zero persistence in the quality of a given job relationship is unrealistic, and greatly alters the incentives involved in promoting a worker to permanence. More importantly, business cycle dynamics are very different in a model like ours, with persistent match-specific productivity, as Mortensen and Pissarides (1994) showed: economic expansions lead to the accumulation of temporary workers in "fragile" jobs which are destroyed en masse as soon as the state of the economy worsens. The absence of "fragile" jobs implied by the i.i.d. productivity model of Sala et al. (2009) explains why they failed to find any impact of duality per se on employment volatility. The cost of allowing for job fragility in the present paper is that our dynamic simulation must keep track of the distribution of productivity over time; our computational method follows Costain and Jansen (2009).

The next section presents our model and describes its basic implications for hiring and firing. Section 3 discusses the model's steady state, including the steady-state effects of labor market policy. In Section 4 we analyze dynamics, assuming aggregate shocks follow a two-state Markov process (the $N$-state case is studied in Appendix 1). We perform simulation exercises to explore how employment volatility varies across different policy scenariosin Section 5. The final section concludes.

\section{The model}

Here we define a version of Mortensen and Pissarides' (1994) continuous-time model of job creation and destruction in which we allow for two classes of contracts, temporary and permanent. 


\subsection{Productivity of matches}

The productivity of a matched worker-firm pair is assumed to be the sum of an idiosyncratic component $z$ and an aggregate component $y$. The distribution of idiosyncratic productivity for new jobs is $G_{0}(z)$. As long as a given match continues, shocks to its idiosyncratic productivity arrive with probability $\lambda$ per unit of time. New values of productivity are then drawn from the distribution $G(z)$. For simplicity, we assume the two distributions are the same: $G_{0}=G{ }^{4}$

Total match productivity is $z+y$, where $y$ is an aggregate random variable with mean $\bar{y}$ which takes $N$ possible values $y_{1}<y_{2}<\ldots<y_{N}$. Shocks to aggregate productivity arrive with probability $\mu$ per unit of time. When an aggregate shock occurs, the probability of the new state $y_{j}$ conditional on the current state $y_{i}$ is $M_{y_{j} \mid y_{i}}$. We can arrange these probabilities into a Markov matrix as follows:

$$
M=\left(\begin{array}{ccc}
M_{y_{1} \mid y_{1}} & & M_{y_{1} \mid y_{N}} \\
& \cdots & \\
M_{y_{N} \mid y_{1}} & & M_{y_{N} \mid y_{N}}
\end{array}\right)
$$

Here column $j$ describes the probabilities of the $N$ possible successors of the current state, so the columns of $M$ must sum to one. For concise notation we will sometimes abbreviate $\mu_{j \mid i} \equiv \mu M_{y_{j} \mid y_{i}}$. Under this notation, we have $\sum_{k=1}^{N} \mu_{k \mid i}=\mu$.

We also assume that the process for $y$ exhibits first-order stochastic dominance, in the following sense, so that a higher $y$ now makes a higher $y$ more likely in the future too.

Assumption $1 M$ is a Markov matrix, with all elements strictly positive. $M$ has the property that for any two nonnegative vectors $v$ and $v^{\prime}$, if $v \geq v^{\prime}$, then $(I+M) v \geq$ $(I+M) v^{\prime}$, where $I$ is the $N$-by- $N$ identity matrix.

\subsection{Matching process}

The total labor force is normalized to one. In each unit of time, a mass $\rho$ of new workers is born, and fraction $\rho$ of existing workers (employed or unemployed) retire and exit the labor pool.

Firms may open any number of vacant jobs; keeping a job open costs $c$ per unit of time. The total number of vacant jobs is $v$. Unemployed workers produce

\footnotetext{
${ }^{4}$ It would be straightforward to allow for accumulation of match-specific experience by assuming $G$ dominates $G_{0}$ in the sense of first-order stochastic dominance. See for example Mortensen and Nagypal (Scand JE 2008).
} 
output $b$. We assume some jobs are more productive than unemployment; that is, $G(b-\bar{y})<1$. Only unemployed workers can search. Search per se is costless. Newly matched worker-firm pairs can separate costlessly, which implies that in equilibrium, the value of unemployment is less than or equal to the value of being newly matched. Therefore, in equilibrium, all unemployed workers search.

Searching workers $u$ and vacant jobs $v$ meet according to the matching function

$$
m(u, v) \text {. }
$$

Assuming constant returns to scale, the instantanous meeting probability for vacancies is given by

$$
\frac{m(u, v)}{v}=m\left(\frac{1}{v / u}, 1\right) \equiv q(\theta)
$$

where $\theta \equiv v / u$ is labor market tightness. The meeting probability for unemployed workers is $p(\theta)=\theta q(\theta)$.

Both workers and firms can decide to separate from their current matches, subject to legal costs which will be discussed below. There is no recall of matches. That is, if either agent chooses to separate, both agents become unmatched, and can only become matched again with a new partner by means of the matching function.

\subsection{Labor market policy}

A firm that creates a new job may choose to hire a worker under two types of contract: a fixed-term contract we will call "temporary", or an open-ended contract we will call "permanent". Temporary contracts can be freely destroyed at any time. However, if a contract is initially of the temporary type, this contract status expires with probability $\delta$ per period. Upon expiry the firm must decide whether to fire the worker or promote him/her to a permanent contract.

When a firm fires a worker who has a permanent contract, it must pay a firing cost $F$. We assume $F$ represents a loss of income to the matched pair. In other words, $F$ is a "red-tape" cost, instead of an income transfer from the firm to the worker.

\subsection{Match surplus and wage bargaining}

The productivity processes $y$ and $z$ are the only shocks in our model. We conjecture that agents' values are functions of productivity only, as in Mortensen-Pissarides (1994). Therefore we write the values of unemployed workers and vacant jobs as $U(y)$ and $V(y)$, respectively, in terms of aggregate productivity only. We define 
firms' values of temporary and permanent jobs as $J^{T}(z, y)$ and $J^{P}(z, y)$, and workers' values of temporary and permanent jobs as $W^{T}(z, y)$ and $W^{P}(z, y)$. We postpone statement of the associated Bellman equations to Sections 3 and 4.

Since pairs with temporary contracts can separate costlessly, the surplus of a worker in a temporary job is $W^{T}(z, y)-U(y)$; the firm's surplus for this job is $J^{T}(z, y)-V(y)$; and the total surplus of a temporary job is

$$
S^{T}(z, y)=W^{T}(z, y)-U(y)+J^{T}(z, y)-V(y) .
$$

A worker can also separate costlessly from a permanent job, so the worker's surplus from this job is $W^{P}(z, y)-U(y)$. However, when a permanent job separates, the firm must pay the firing cost $F$. Thus the outside option of a firm with a permanent job is $-F$, and its surplus relative to this outside option is $J^{P}(z, y)-V(y)+F$. Therefore the total surplus of a permanent job is

$$
S^{P}(z, y)=W^{P}(z, y)-U(y)+J^{P}(z, y)-V(y)+F .
$$

We assume that the wage is determined by Nash bargaining between a firm and its new hires, treating separation as the outside option. In addition, the wage is updated whenever new information arrives that affects the value of the match, so the surplus sharing equations hold at all times. The worker's bargaining share is $\eta$. These assumptions imply that the surplus-sharing rule for temporary contracts is

$$
J^{T}(z, y)-V(y)=(1-\eta) S^{T}(z, y)
$$

whereas the rule for permanent workers is given by

$$
J^{P}(z, y)-V(y)+F=(1-\eta) S^{P}(z, y)
$$

Hence there are distinct wage functions for temporary and permanent jobs, $w_{T}(z, y)$ and $w_{P}(z, y)$.

\subsection{Job creation and job destruction}

Firms open vacancies until their value $V(y)$ is driven down to zero. The cost of a vacancy is $c$ per period, and the benefit of a vacancy is the creation of a new match with probability $q(\theta(y))$ per period. This new match may, in principle, be hired in a temporary or permanent contract, so that the firm obtains value $J^{T}(z, y)$ or $J^{P}(z, y)$, or the firm may decide not to hire the worker, obtaining value 0 . Thus, 
using the sharing rule (3) for temporary contracts, the zero profit condition $V(y)=0$ is equivalent to the following job creation equation:

$$
\frac{c}{q(\theta(y))}=(1-\eta) \int_{0}^{\infty} \max \left\{S^{T}(z, y), S^{P}(z, y), 0\right\} d G(z) .
$$

Separations are determined by three productivity thresholds above which matches continue in a given state $y$, depending on the current contracting situation. The first is the threshold for temporary matches, $R^{T}(y)$, such that any job eligible for a temporary contract continues as long as $z \geq R^{T}(y)$. This threshold satisfies

$$
J^{T}\left(R^{T}(y), y\right)=0 \quad \rightarrow \quad S^{T}\left(R^{T}(y), y\right)=W^{T}\left(R^{T}(y), y\right)-U(y)=0
$$

Note therefore that hiring and continuation of temporary contracts is jointly optimal: it occurs if and only if both parties benefit.

Second, there is a threshold productivity relevant at the moment temporary status expires, $R^{C}(y)$, such that any job which is no longer eligible for temporary status is converted to permanence if $z \geq R^{C}(y)$. This threshold is determined by

$$
J^{P}\left(R^{C}(y), y\right)=0 \quad \rightarrow \quad S^{P}\left(R^{C}(y), y\right)=\frac{F}{1-\eta}>0
$$

At $R^{C}(y)$, the firm is indifferent between making the worker permanent and destroying the job at zero cost.

Note, therefore, that the promotion decision is not bilaterally efficient. If a firm were to promote a worker with productivity $z=R^{C}(y)-\varepsilon$, for some tiny $\varepsilon$, the firm's value would become infinitesimally negative, but the worker's value would remain strictly positive, implying a net gain for the pair. This Pareto improvement would be possible if matched pairs could sign binding wage contracts prior to promotion. The optimal contract would commit promoted workers to a lower wage, implicitly sharing expected firing costs between workers and firms. Here such commitment is impossible: a firm expects permanent workers to bargain up the wage, taking advantage of the firm's less favorable threat point, and may therefore may choose to fire a worker even when that worker would have strictly positive surplus after promotion.

Finally, there is a threshold productivity $R^{P}(y)$ for firing of permanent jobs, such that jobs with permanent status continue as long as $z \geq R^{P}(y)$, determined by

$$
J^{P}\left(R^{P}(y), y\right)+F=0 \quad \rightarrow \quad S^{P}\left(R^{P}(y), y\right)=W^{P}\left(R^{P}(y), y\right)-U(y)=0
$$

Note that from the matched pair's perspective, firing of permanent contracts is jointly efficient; it occurs only if both parties benefit. But this comment takes as given and sunk the cost $F$, which is a policy parameter. So while separation is jointly efficient from the pair's perspective conditional on policy, it is not socially efficient. 


\subsection{Equilibrium}

In equations (5)-(8), we see that the job creation and destruction decisions imply four equations, for each aggregate state $y$, to determine job tightness $\theta(y)$ and the reservation thresholds $R^{T}(y), R^{C}(y)$, and $R^{P}(y)$. Moreover, all these conditions depend on the surplus functions $S^{T}(z, y)$ and $S^{P}(z, y)$. Later we will see how to calculate the surplus functions in terms of the reservation productivities, allowing us to substitute the surplus functions out of (5)-(8).

Therefore, the system (5)-(8) consists of $4 N$ equations that determine the $4 N$ unknowns $\theta(y), R^{T}(y), R^{C}(y)$, and $R^{P}(y)$ for all aggregate states $y$. A solution of this equation system is an equilibrium of our model.

\subsection{Characterizing the reservation thresholds}

Determining the order of all the reservation thresholds is nontrivial in general, but we can deduce several key facts from first principles. To understand the ordering, it helps to reason on the basis of the joint payoff to the pair, which is just a discounted flow of output $z+y$ minus the worker's cost of employment (later we will see that this cost equals $b+\frac{\eta c \theta(y)}{1-\eta}$ ), ending with a lump sum payment of 0 (if the contract is temporary) or $F$ (if the contract is permanent).

First, compare the expected payoff to a matched pair in a temporary contract with that to a matched pair in a permanent contract. Considering all possible future realizations of the process for $z+y$, the expected flow of income in these two pairs is the same up to the moment of separation. The only difference is that upon separation, the pair in a permanent contract loses $F$. Therefore the expected payoff to the pair is lower in the case of a permanent contract, that is, $W^{P}(z, y)+J^{P}(z, y) \leq$ $W^{T}(z, y)+J^{T}(z, y)$. Moreover, offering the worker a permanent contract lowers the firm's threat point from 0 to $-F$. Since offering a permanent contract diminishes the pair's joint payoff, and also lowers the firm's threat point, a firm always prefers to offer a temporary contract if legally permitted to do so. That is:

Proposition 2 If a firm can choose between hiring a worker on a temporary contract and hiring the same worker on a permanent contract, it chooses the temporary contract.

Next, note that a higher current value of $z$ raises the payoff to the match until a new idiosyncratic shock arrives, or until the match separates. If a new idiosyncratic shock arrives, its value is uncorrelated with the current $z$. And separation is less likely to occur if the current $z$ is higher (since separation occurs only when surplus falls sufficiently low). Therefore, 
Lemma 3 The surplus functions for temporary and permanent matches are increasing in $z$ :

$$
\text { for all } y, z_{1} \leq z_{2} \text { implies } S^{T}\left(z_{1}, y\right) \leq S^{T}\left(z_{2}, y\right) \text { and } S^{P}\left(z_{1}, y\right) \leq S^{P}\left(z_{2}, y\right)
$$

Proof. See Appendix 1.2-1.3.

All three types of reservation thresholds are determined by equating surplus to a constant: $S^{T}\left(R^{T}(y), y\right)=0, S^{P}\left(R^{C}(y), y\right)=\frac{F}{1-\eta}$, and $S^{P}\left(R^{P}(y), y\right)=0 . \quad$ In particular, since $R^{C}(y)$ is associated with a higher level of surplus than $R^{P}(y)$, we conclude that $R^{P}(y) \leq R^{C}(y)$ for any $y$.

To determine where the temporary hiring threshold lies relative to the other two thresholds, note that firms are initially able to choose between hiring on a temporary and permanent basis, and we have argued they strictly prefer temporary hiring (assuming $z$ is sufficiently high; otherwise they prefer to let the worker go). Expiry of a temporary contract simply shrinks the firm's choice set, eliminating its preferred choice, requiring it instead to hire on a permanent basis (or to let the worker go). Thus expiry of a temporary contract makes a match strictly less valuable to the firm; and therefore a firm is less willing to promote than it is to hire, that is, $R^{T}(y) \leq R^{C}(y)$.

Finally, consider the relation between $R^{P}(y)$ and $R^{T}(y)$. We already know a matched pair has a lower expected payoff in a permanent contract than in a temporary contract: $W^{P}(z, y)+J^{P}(z, y) \leq W^{T}(z, y)+J^{T}(z, y)$. This occurs because some permanent relationships continue, in order to avoid paying the cost $F$, even when $W^{P}(z, y)+J^{P}(z, y) \leq U(y)$. But therefore separation occurs whenever the loss exceeds $F$, implying $W^{P}(z, y)+J^{P}(z, y)+F \geq U(y)$ as long as a match continues. Thus, considering all future paths starting from a given state $(z, y)$, the payoff to a permanent contract is lowered along some realizations by an amount that never exceeds $F$, implying $W^{P}(z, y)+J^{P}(z, y)+F \geq W^{T}(z, y)+J^{T}(z, y)$. But therefore the surplus of a permanent contract, which includes $F$, is higher than that of a temporary contract evaluated in the same state: $S^{P}(z, y) \geq S^{T}(z, y)$. Thus given Lemma 3, together with the definition of the hiring thresholds $S^{P}\left(R^{P}(y), y\right)=S^{T}\left(R^{T}(y), y\right)=0$, we must have $R^{P}(y) \leq R^{T}(y)$.

For notational simplicity we will often abbreviate $R^{i}\left(y_{j}\right) \equiv R_{j}^{i}$ for $i \in\{T, C, P\}$ and $j \in\{1,2, \ldots, N\}$. We can summarize our findings up to now as follows:

Proposition 4 For each aggregate state $y_{j}, j \in\{1,2, \ldots, N\}$, the firing threshold for permanent contracts lies below the hiring/firing threshold for temporary contracts, which lies below the promotion threshold:

$$
R_{j}^{P} \leq R_{j}^{T} \leq R_{j}^{C} .
$$


Second, suppose Assumption 1 holds. Then a higher current value of $y$ raises the payoff to the match until a new aggregate shock arrives, or until the match separates; moreover, it predicts a higher $y$ when the next shock arrives, and makes separation less likely. Therefore, it seems likely that that match surplus increases with the aggregate shock $y$. However, there is an offsetting effect: a higher $y$ should also increase the value of unemployment. From here on, we will assume that this offsetting effect is not strong enough to outweigh the direct effect of higher productivity. This assumption can be written as

Assumption 5 For each $i=1,2, \ldots N-1$, the relationship between productivity and tightness satisfies

$$
y_{i+1}-y_{i}>\frac{\eta c \theta\left(y_{i+1}\right)}{1-\eta}-\frac{\eta c \theta\left(y_{i}\right)}{1-\eta} .
$$

On the right-hand side, the quantity $\eta c \theta(y) /(1-\eta)$ represents the value of searching for a job (as we will show later). Therefore, Assumption 5 simply says that the effect of the cycle on the productivity of an employed worker is larger than the effect of the cycle on the value of searching for a job. In Appendix 1.4, we will show for the special case of $N=2$ and a small difference between $y_{1}$ and $y_{2}$ that Assumption 5 must hold in equilibrium (moreover, it also holds in our simulated examples). Proving that it holds more generally is difficult, so in general we just take it as an assumption. Given this assumption, we can then characterize many other properties of equilibrium. In particular,

Lemma 6 Suppose Assumptions 1 and 5 are satisfied. Then the surplus functions for temporary and permanent matches are increasing in $y$ :

$$
\text { for all } z, y_{1} \leq y_{2} \text { implies } S^{T}\left(z, y_{1}\right) \leq S^{T}\left(z, y_{2}\right) \text { and } S^{P}\left(z, y_{1}\right) \leq S^{P}\left(z, y_{2}\right)
$$

Proof. See Appendix 1.4.

Notice again that all three types of reservation thresholds are determined by equating surplus to a constant:

$$
S^{T}\left(R^{T}(y), y\right)=0, S^{P}\left(R^{C}(y), y\right)=\frac{F}{1-\eta}, \text { and } S^{P}\left(R^{P}(y), y\right)=0 .
$$

Geometrically, since we have shown that the surplus functions are increasing in $z$, this means a higher $y$ requires a lower reservation threshold $R^{i}(y)$ for each type of threshold $i \in\{T, C, P\}$. Therefore we have

Proposition 7 For each type of threshold $R^{i}, i \in\{T, C, P\}$, the threshold is a decreasing function of $y$ :

$$
R_{N}^{i} \leq R_{N-1}^{i} \leq \ldots \leq R_{1}^{i}
$$




\subsection{Employment and productivity dynamics}

Once $R^{P}(y), R^{C}(y), R^{T}(y)$, and $\theta(y)$ are known, we can simulate employment dynamics. In state $y$, unemployed workers become employed at rate $\left(1-G\left(R^{T}(y)\right)\right) p(\theta(y))$. Conditional on idiosyncratic productivity shocks or the expiry of temporary contracts, continuation is determined by the reservation productivities. Also, whenever the aggregate state decreases $\left(y(t)=y_{i}>y(t+d t)=y_{j}\right)$, there is a noninfinitesimal mass of firing, as all temporary employees in the interval $\left[R_{i}^{T}, R_{j}^{T}\right)$ and all permanent employees in the interval $\left[R_{i}^{P}, R_{j}^{P}\right)$ suddenly separate.

Note that the probability of promotion and/or separation of a match with state $(z, y)$ does not depend on the exact value of $z$; it only depends on where $z$ lies relative to the reservation thresholds. We state this formally as Proposition 8a:

Proposition 8 Consider an interval $I=\left[R^{a}\left(y_{j}\right), R^{b}\left(y_{k}\right)\right)$ formed by two adjacent reservation thresholds, that is, $a, b \in\{T, C, P\}$ and $j, k \in\{1,2, \ldots, N\}$, with no other reservation threshold between these two.

(a.) Consider two temporary matches $h$ and $i$ with productivities $z_{h t}$ and $z_{i t}$ at time $t$. If $z_{h t} \in I$ and $z_{i t} \in I$, then matches $h$ and $i$ face the same probabilities of separation and promotion and of drawing any new productivity shock $z^{\prime}$.

Let the number of temporary matches in interval I at time $t$ be $n_{t}^{T}(I)>0$. Then, in the limit as $t \rightarrow \infty$, the probability distribution of productivity among temporary matches has the following properties:

(b.) the density over $z$ for temporary matches satisfying $z \in I$ at $t$ is $G^{\prime}(z) / n_{t}^{T}(I)$; (c.) the average productivity of temporary matches in I at $t$ is $\int_{R^{a}\left(y_{j}\right)}^{R^{b}\left(y_{k}\right)} z \frac{G^{\prime}(z)}{n_{t}^{T}(I)} d z$.

Formulas analogous to (a), (b), and (c) hold for permanent matches as well.

Parts (b) and (c) of the proposition show the simplest way to keep track of the distribution of employment and productivity over time. The probabilities of any given change in the state of a given match depend only on which pair of reservation thresholds current match productivity lies between. Therefore to know how the productivity distribution is evolving it suffices to keep track of the mass of employment on each interval defined by two adjacent reservation thresholds.

Of course, we could analyze the dynamics of the model from any arbitrary initial productivity distribution; in this case there will initially be transition dynamics as the productivity distribution gradually converges to its long run form. But in the long run, the productivity distribution converges to a very simple form, as stated in Prop. 8b: the distribution of $z$ on the interval between two adjacent reservation thresholds is just a truncated version of the ex ante productivity distribution $G(z)$. 
The reason this proposition holds is that temporary matches entering any interval of this form are initially drawn from distribution $G$; thereafter all transitions in employment status are conditional on $z$ only insofar as they depend on which interval $z$ lies in. Thus, while the overall distribution of productivity among job matches changes over time, due to the effects of aggregate shocks, nonetheless the form of the productivity distribution in the interval between any two adjacent reservation thresholds is always just a truncation of $G$. Keeping track of the mass of employment on each interval of this type therefore suffices to know the full productivity distribution at all times.

\section{$3 \quad$ Steady state}

Before addressing the full dynamics or our model, we first study its steady state, in which aggregate productivity takes a fixed value $\bar{y}$, and only idiosyncratic productivity $z$ is hit by shocks. We indicate steady state quantities by eliminating the argument $y$ and adding the subscript ss.

\subsection{Value functions}

\subsubsection{Jobs}

We begin by deriving the Bellman equations that govern the value functions of workers and firms. Let $\mathbf{1}(x)$ be an indicator function that equals one if $x$ is true and zero otherwise. A firm's value of a temporary job, $J_{s s}^{T}(z)$, must satisfy

$$
(r+\rho) J_{s s}^{T}(z)=z+\bar{y}-w_{s s}^{T}(z)+\delta\left[\mathbf{1}\left(z \geq R_{s s}^{C}\right) J_{s s}^{P}(z)-J_{s s}^{T}(z)\right]+\lambda\left[\int_{R_{s s}^{T}} J_{s s}^{T}(x) d G(x)-J_{s s}^{T}(z)\right]
$$

Note that the job value is discounted both by the pure time preference rate $r$ and by retirement rate $\rho$ (which is simply treated as exit from the model). Besides earning income net of wages $z+\bar{y}-w_{s s}^{T}(z)$ in each period, the firm also anticipates that temporary contracts expire with probability $\delta$ per period, in which case the job becomes permanent if $z \geq R_{s s}^{C}$; otherwise the job separates and has value $V_{s s}=0$. Also, the firm expects idiosyncratic shocks to arrive at rate $\lambda$; if the new level of productivity exceeds the threshold $R_{s s}^{T}$ the match continues; otherwise it separates, yielding value $V_{s s}=0$.

The value of a permanent job, $J_{s s}^{P}(z)$, satisfies a similar Bellman equation:

$$
(r+\rho) J_{s s}^{P}(z)=z+\bar{y}-w_{s s}^{P}(z)+\lambda\left[\int_{R_{s s}^{P}} J_{s s}^{P}(x) d G(x)-G\left(R_{s s}^{P}\right) F-J_{s s}^{P}(z)\right] .
$$


We see here that when an idiosyncratic shock arrives, if it lies below threshold $R_{s s}^{P}$ it causes firing and therefore the firm must pay $F$.

Firms' match surplus

Given free entry, which implies $V_{s s}=0$, the firm's surplus from a temporary job is just the value of that job, $J_{s s}^{T}(z)$. Simplifying our earlier equation,

$$
(r+\rho+\delta+\lambda) J_{s s}^{T}(z)=z+\bar{y}-w_{s s}^{T}(z)+\delta \mathbf{1}\left(z \geq R_{s s}^{C}\right) J_{s s}^{P}(z)+\lambda \int_{R_{s s}^{T}} J_{s s}^{T}(x) d G(x) .
$$

Since the outside option of a firm with a permanent contract is the payment of the firing cost (i.e. the value $-F$ ), the surplus associated with a permanent job is $J_{s s}^{P}(z)+F$. Rearranging our earlier Bellman equation, we obtain

$$
(r+\rho+\lambda)\left(J_{s s}^{P}(z)+F\right)=z+\bar{y}-w_{s s}^{P}(z)+(r+\rho) F+\lambda \int_{R_{s s}^{P}}\left(J_{s s}^{P}(x)+F\right) d G(x) .
$$

\subsubsection{Workers}

A worker's value of employment under a temporary contract $W_{s s}^{T}(z)$ satisfies

$$
\begin{aligned}
(r+\rho) W_{s s}^{T}(z)= & w_{s s}^{T}(z)+\delta\left[\mathbf{1}\left(z \geq R_{s s}^{C}\right) W_{s s}^{P}(z)+\mathbf{1}\left(z<R_{s s}^{C}\right) U-W_{s s}^{T}(z)\right] \\
& +\lambda\left[\int_{R_{s s}^{T}} W_{s s}^{T}(x) d G(x)+G\left(R_{s s}^{T}\right) U_{s s}-W_{s s}^{T}(z)\right]
\end{aligned}
$$

where $W_{s s}^{P}(z)$ is the worker's value of permanent employment:

$$
(r+\rho) W_{s s}^{P}(z)=w_{s s}^{P}(z)+\lambda\left[\int_{R_{s s}^{P}} W_{s s}^{P}(x) d G(x)+G\left(R_{s s}^{P}\right) U_{s s}-W_{s s}^{P}(z)\right]
$$

and $U_{s s}$ is a worker's value of unemployment, which satisfies

$$
(r+\rho) U_{s s}=b+p\left(\theta_{s s}\right) \int_{R_{s s}^{T}}^{\infty}\left(W_{s s}^{T}(z)-U_{s s}\right) d G(z) .
$$

Workers' match surplus

A worker's surplus from a temporary job is $W_{s s}^{T}(z)-U_{s s}$. Rearranging the previous equations, we obtain

$$
\begin{gathered}
(r+\rho+\delta+\lambda)\left(W_{s s}^{T}(z)-U_{s s}\right)=w_{s s}^{T}(z)-b-p\left(\theta_{s s}\right) \int_{R_{s s}^{T}}^{\infty}\left(W_{s s}^{T}(x)-U_{s s}\right) d G(x) \\
+\delta \mathbf{1}\left(z \geq R_{s s}^{C}\right)\left(W_{s s}^{P}(z)-U_{s s}\right)+\lambda \int_{R_{s s}^{T}}\left(W_{s s}^{T}(x)-U_{s s}\right) d G(x)
\end{gathered}
$$


Likewise, a worker's surplus from a permanent job is $W_{s s}^{P}(z)-U_{s s}$, satisfying

$$
\begin{aligned}
(r+\rho+\lambda)\left(W_{s s}^{P}(z)-U_{s s}\right)= & w_{s s}^{P}(z)-b-p\left(\theta_{s s}\right) \int_{R_{s s}^{T}}^{\infty}\left(W_{s s}^{T}(x)-U_{s s}\right) d G(x) \\
& +\lambda \int_{R_{s s}^{P}}\left(W_{s s}^{P}(x)-U_{s s}\right) d G(x) .
\end{aligned}
$$

\subsection{Surplus functions}

It now simplifies the analysis to combine the Bellman equations to focus only on total match surplus. We can also use the zero-profit condition (5) to substitute as follows:

$$
p\left(\theta_{s s}\right) \int_{R_{s s}^{T}}^{\infty}\left(W_{s s}^{T}(x)-U_{s s}\right) d G(x)=\theta_{s s} q\left(\theta_{s s}\right) \eta \int_{R_{s s}^{T}}^{\infty} S_{s s}^{T}(x) d G(x)=\eta c \theta_{s s} /(1-\eta) .
$$

Summing the equations for firms' and workers' surpluses, the Bellman equations governing total match surplus for temporary and permanent jobs are

$$
\begin{aligned}
& (r+\rho+\lambda+\delta) S_{s s}^{T}(z)=z+\bar{y}-b-\frac{\eta c \theta_{s s}}{1-\eta}+\delta \mathbf{1}\left(z \geq R_{s s}^{C}\right)\left(S_{s s}^{P}(z)-F\right)+\lambda \int_{R_{s s}^{T}} S_{s s}^{T}(x) d G(x) \\
& (r+\rho+\lambda) S_{s s}^{P}(z)=z+\bar{y}-b+(r+\rho) F-\frac{\eta c \theta_{s s}}{1-\eta}+\lambda \int_{R_{s s}^{P}} S_{s s}^{P}(x) d G(x)
\end{aligned}
$$

A key point to notice here is that we can differentiate through (9)-(10) with respect to $z$ at most points, except at $R_{s s}^{C}$, where (9) shows a sudden change in slope. We observe that $S_{s s}^{P}(z)$ is linear, and $S_{s s}^{T}(z)$ is piecewise linear. The slopes are

$$
\begin{aligned}
& \frac{d S_{s s}^{T}(z)}{d z}= \begin{cases}\frac{1}{r+\rho+\lambda+\delta}, & z<R_{s s}^{C} \\
\frac{1}{r+\rho+\lambda}, & z \geq R_{s s}^{C}\end{cases} \\
& \frac{d S_{s s}^{P}(z)}{d z}=\frac{1}{r+\rho+\lambda}
\end{aligned}
$$

Besides a change in slope, (9) shows that the temporary match surplus is discontinuous at $z=R_{s s}^{C}$. Note that $J_{s s}^{P}\left(R_{s s}^{C}\right)=0$ implies $S_{s s}^{P}\left(R_{s s}^{C}\right)-F=\frac{\eta}{1-\eta} F$. Plugging this into (9), the jump in $S_{s s}^{T}(z)$ at $z=R_{s s}^{C}$ equals $(r+\rho+\lambda+\delta)^{-1} \frac{\delta \eta}{1-\eta} F$. This discontinuity represents the sudden decrease in the pair's joint value as $z$ falls below $R^{C}(y)$, because of firms' unwillingness to promote workers below this threshold. 
Combining all this information, and setting $S_{s s}^{P}\left(R_{s s}^{P}\right)=S_{s s}^{T}\left(R_{s s}^{T}\right)=0$, we can write the surplus functions explicitly conditional on the reservation productivities:

$$
\begin{aligned}
& S_{s s}^{T}(z)= \begin{cases}\frac{z-R_{s s}^{T}}{r+\rho+\lambda+\delta}, & z<R_{s s}^{C} \\
\frac{R_{s s}^{C}-R_{s s}^{T}+\delta \eta F /(1-\eta)}{r+\rho+\lambda+\delta}+\frac{z-R_{s s}^{C}}{r+\rho+\lambda}, & z \geq R_{s s}^{C}\end{cases} \\
& S_{s s}^{P}(z)=\frac{z-R_{s s}^{P}}{r+\rho+\lambda}
\end{aligned}
$$

\subsection{Steady state equilibrium}

Equilibrium requires that the job creation and destruction equations (5)-(8) be satisfied when we plug in the Bellman equations (9)-(10) that define the surplus. The steady state job creation equation is simply

$$
\frac{c}{q\left(\theta_{s s}\right)}=(1-\eta) \int_{R_{s s}^{T}} S_{s s}^{T}(x) d G(x) .
$$

Next, since $R^{T}(y)<R^{C}(y)$ for any $y$, we have $\mathbf{1}\left(z \geq R_{s s}^{C}\right)=0$ at $z=R_{s s}^{T}$. Therefore the $\delta$ term cancels out of the temporary job destruction condition (7), leaving

$$
0=R_{s s}^{T}+\bar{y}-b-\frac{\eta c \theta_{s s}}{1-\eta}+\lambda \int_{R_{s s}^{T}} S_{s s}^{T}(x) d G(x) .
$$

The steady state job destruction condition for permanent workers is

$$
0=R_{s s}^{P}+\bar{y}-b+(r+\rho) F-\frac{\eta c \theta_{s s}}{1-\eta}+\lambda \int_{R_{s s}^{P}} S_{s s}^{P}(x) d G(x) .
$$

Finally, at the promotion threshold we have

$$
(r+\rho+\lambda) \frac{F}{1-\eta}=R_{s s}^{C}+\bar{y}-b+(r+\rho) F-\frac{\eta c \theta_{s s}}{1-\eta}+\lambda \int_{R_{s s}^{P}} S_{s s}^{P}(s) d G(x) .
$$

but it is simpler to subtract this equation from (15) and thus replace it by

$$
R_{s s}^{C}=R_{s s}^{P}+(r+\rho+\lambda) \frac{F}{1-\eta}
$$

These equations can be simplified further by plugging the explicit surplus formulas (11)-(12) into the integrals on the right-hand side, leaving just four unknowns: $R_{s s}^{T}$, 
$R_{s s}^{C}, R_{s s}^{P}$, and $\theta_{s s}$. Thus steady state equilibrium can be calculated by solving the system of four equations in four unknowns (13)-(16). ${ }^{5}$

\subsection{Steady state employment}

Given $R_{s s}^{P}, R_{s s}^{C}, R_{s s}^{T}$, and $\theta_{s s}$, we can also calculate employment. By Prop. 8a, it suffices to keep track of employment on intervals bounded by reservation productivities. Thus, define $I_{1}=\left[R_{s s}^{C}, \infty\right)$ and $I_{2}=\left[R_{s s}^{T}, R_{s s}^{C}\right)$, and let $n_{t}^{T}(I)$ be temporary employment on interval $I$ at time $t$. Using this notation, the transitional dynamics in the absence of aggregate shocks are:

$$
\begin{aligned}
\dot{u}_{t} & =\rho+\delta n_{t}^{T}\left(I_{2}\right)+\lambda G\left(R_{s s}^{T}\right) n_{t}^{T}+\lambda G\left(R_{s s}^{P}\right) n_{t}^{P}-\left[\rho+\left(1-G\left(R_{s s}^{T}\right)\right) p\left(\theta_{s s}\right)\right] u_{t} \\
\dot{n}_{t}^{T}\left(I_{1}\right) & =\left(1-G\left(R_{s s}^{C}\right)\right)\left[p\left(\theta_{s s}\right) u_{t}+\lambda n_{t}^{T}\right]-(\rho+\delta+\lambda) n_{t}^{T}\left(I_{1}\right) \\
\dot{n}_{t}^{T}\left(I_{2}\right) & =\left(G\left(R_{s s}^{C}\right)-G\left(R_{s s}^{T}\right)\right)\left[p\left(\theta_{s s}\right) u_{t}+\lambda n_{t}^{T}\right]-(\rho+\delta+\lambda) n_{t}^{T}\left(I_{2}\right) \\
\dot{n}_{t}^{P} & =\delta n_{t}^{T}\left(I_{1}\right)-\left(\rho+\lambda G\left(R_{s s}^{P}\right)\right) n_{t}^{P}
\end{aligned}
$$

These equations are consistent with a constant labor force at all times, satisfying

$$
\begin{aligned}
u_{t} & =1-n_{t}^{T}-n_{t}^{P}, \\
n_{t}^{T} & =n_{t}^{T}\left(I_{1}\right)+n_{t}^{T}\left(I_{2}\right) .
\end{aligned}
$$

In steady state, these equations imply ${ }^{6}$

$$
\begin{gathered}
n_{s s}^{T}=\frac{p\left(\theta_{s s}\right)\left(1-G\left(R_{s s}^{T}\right)\right)}{\rho+\delta+\lambda G\left(R_{s s}^{T}\right)} u_{s s} \\
n_{s s}^{P}=\frac{\delta\left(1-G\left(R_{s s}^{C}\right)\right)}{\left(\rho+\lambda G\left(R_{s s}^{P}\right)\right)\left(1-G\left(R_{s s}^{T}\right)\right)} n_{s s}^{T} \\
u_{s s}=\frac{\rho+\delta+\lambda G\left(R_{s s}^{T}\right)}{\rho+\delta+\lambda G\left(R_{s s}^{T}\right)+p\left(\theta_{s s}\right)\left[1-G\left(R_{s s}^{T}\right)+\frac{\delta\left(1-G\left(R_{s s}^{C}\right)\right)}{\rho+\lambda G\left(R_{s s}^{P}\right)}\right]}
\end{gathered}
$$

${ }^{5}$ It might seem easier to plug (11)-(12) directly into the creation and destruction equations (5)(8). However, by doing this, equations (6) and (8) both take the form $0=0$, leaving us with only two equations to determine the four unknowns $R_{s s}^{T}, R_{s s}^{C}, R_{s s}^{P}$, and $\theta_{s s}$. By plugging (11)-(12) into (13)-(16) instead, we end up with four nontrivial equations to determine equilibrium.

${ }^{6}$ Note that in principle we may find $R_{s s}^{P}<0$, so that $G\left(R_{s s}^{P}\right)=0$. Thus the formula for $n_{s s}^{P}$ shows that the stock of permanent employees can be infinitely larger than the stock of temporary employees unless there is a nonzero flow of retirement $(\rho>0)$. Therefore considering $\rho>0$ allows us to explore a larger parameter space - in particular, it implies a well-defined steady state even with large values of $F$ which firms never or almost never choose to pay. 


\begin{tabular}{|l|l|l|}
\hline Description & Parameter & Value \\
\hline Real interest rate & $r$ & 0.0017 \\
Rate of retirement and rebirth & $\rho$ & 0.0021 \\
Matching and bargaining & & \\
Vacancy posting cost & $c$ & $0.3 E z$ \\
Unemployment elasticity of matching & $\epsilon$ & 0.5 \\
Coefficient of matching function & $\chi$ & 0.3985 \\
Worker bargaining power & $\eta$ & 0.5 \\
Aggregate productivity & & \\
Unemployment productivity & $b$ & $0.8 E z$ \\
Mean aggregate productivity & $E y$ & 0 \\
Transition rate to recession from boom & $\mu_{1 \mid 2}$ & 0.05 \\
Transition rate to boom from recession & $\mu_{2 \mid 1}$ & 0.1 \\
Productivity decrement in recession & $y_{1}-E y$ & -0.04 \\
Productivity increment in boom & $y_{2}-E y$ & 0.02 \\
Idiosyncratic productivity & & \\
Arrival rate of idiosyncratic shocks & $\lambda$ & 0.0203 \\
Standard deviation of log $z$ & $\sigma_{z}$ & 0.0785 \\
Mean of log $z$ & $\mu_{z}$ & 0 \\
Policy & & \\
Firing cost for permanent jobs & $F$ & $1.9366 E z$ \\
Temporary contract expiry rate & $\delta$ & 0.0417 \\
\hline
\end{tabular}

Table 1: Baseline parameterization

\subsection{Calibration}

Parameters are given in Table 1 . We calibrate our model on a monthly frequency. The real interest rate is set to $2 \%$ per annum, or $r=0.0017$ per month. The exogenous retirement rate, $\rho$, is set to 0.0021 , which implies that a worker who does not experience endogenous separations can expect to stay on the same job for 40 years. For most of our sample period, the Spanish labor legislation established that a certain worker could not stay in the same firm under a succession of temporary contracts for more than two years. We thus set the expiry rate, $\delta$, to $1 / 24$.

In the absence of direct evidence on the Spanish matching function, we draw from estimates for other European countries and set the elasticity of the matching function with respect to unemployment, $\varepsilon$, to $0.5 .^{7}$ Following standard practice, we

\footnotetext{
${ }^{7}$ See e.g. Petrongolo and Pissarides (2001).
} 
assume that the Hosios (1990) condition for efficient job creation holds, which implies setting the workers' bargaining power parameter, $\eta$, equal to $\varepsilon$.

Parameters $c$ and $b$ are set relative to the steady-state equilibrium cross-sectional average of worker productivity, $E z$. We set the cost of posting a vacancy, $c$, to 0.30 of average worker productivity, which is roughly the midpoint of estimates suggested in the literature. ${ }^{8}$ The income flow in unemployment, $b$, is often set around $70 \%$ of average worker productivity in US calibrations. ${ }^{9}$ Since unemployment protection is more generous in Spain than in the US, we instead set $b$ to $80 \%$ of average worker productivity. ${ }^{10}$ Following standard practice, we set the mean of the underlying log productivity distribution $\mu=E(\log (z))$ to 0 ; this is simply a normalization to make units easy to interpret.

No direct microeconomic evidence exists for the remaining four parameters, namely the non-transfer component of firing costs $(F)$, the scale parameter in the matching function $(\chi)$, and the parameters governing the arrival rate and the standard deviation of idiosyncratic productivity shocks ( $\lambda$ and $\sigma$, respectively). We calibrate these four parameters using macroeconomic data. In particular, we use quarterly data from the Spanish Encuesta de Población Activa (EPA) to construct series for the stocks of temporary and permanent employment as fractions of the active population, as well as for the quarterly transition probabilities between unemployment and temporary employment, and between permanent employment and unemployment. Our sample period is 2001:Q1-2008:Q3 ${ }^{11}$ We then take sample averages of our four series and find the values of $F, \chi, \lambda$ and $\sigma$ for which the steady state values $n_{s s}^{T}$, $n_{s s}^{P}, \theta_{s s} q\left(\theta_{s s}\right)\left[1-G\left(R_{s s}^{T}\right)\right]$ and $\lambda G\left(R_{s s}^{P}\right)$ are all exactly equal to the sample average of

${ }^{8}$ Shimer (2005) proposes a value of 0.213 , whereas Hall and Milgrom (2008) use a value of 0.43, in both cases as a fraction of average worker productivity.

${ }^{9}$ See e.g. Hall and Milgrom (2008), Costain and Reiter (2008), and Pissarides (2009). As in those papers, we refer to the average productivity in equilibrium among employed workers, not the mean of the ex ante distribution $G$.

${ }^{10}$ Unemployment protection in general includes not only statutory benefits, but also other social mechanisms, such as extended family networks, which Bentolila and Ichino (2008) argue provide higher protection in Mediterranean countries.

${ }^{11}$ The EPA divides the active population in four groups: non-salaried workers, temporary salaried workers, permanent salaried workers, and unemployed workers. Since our model does not include the first group, we assign them to the second and third groups using the same weights as those of temporary and permanent workers in total salaried employment. This way, our empirical rates of unemployment and temporary employment (the latter defined as the share of temporary workers in total salaried employment) remain unchanged.

Also, as is well known, quarterly data on transition rates suffer from aggregation bias (see e.g. Shimer 2008), such that monthly rates are considerably higher than what results from dividing quarterly rates by three. For this reason, in order to obtain estimates of monthly transition rates we rescale the quarterly transition rates by $2 / 3$, rather than simply by $1 / 3$. 
their corresponding empirical counterpart. ${ }^{12}$ This method delivers values of $F=3.1$ times average monthly worker productivity (i.e. about one fourth of average annual worker productivity), $\chi=0.315, \lambda=0.02$ (which implies that idiosyncratic shocks arrive approximately every four years on average) and $\sigma=0.126$.

\subsection{Steady state behavior of dual labor markets}

\subsubsection{Surplus functions}

Figure 1 illustrates the steady state surplus function under the baseline calibration. The surplus for permanent workers is shown in blue; that of temporary workers is in green. Permanent workers' surplus function lies above that of temporary workers; even though permanent contracts have a lower expected payoff, their surplus is higher since it is calculated relative to a lower outside option for the firm.

The reservation thresholds (recall the ordering $R^{P}<R^{T}<R^{C}$ ) are highlighted with red stars. Also, we see a discontinuity in the surplus for temporary workers at $R^{C}$, due to the pairwise inefficiency of separation. For comparison, the lower panel shows the cumulative distribution function of idiosyncratic shocks $z$. We see that somewhat more than half of new matches result in a hire $\left(G\left(R^{T}\right)=0.465\right)$, while promotion to permanence is more selective: promoted workers come from the top $23 \%$ of the unconditional productivity distribution $\left(G\left(R^{C}\right)=0.774\right)$, which is roughly the top two fifths of the distribution of productivity among temporary employees $\left(\frac{1-G\left(R^{C}\right)}{1-G\left(R^{T}\right)}=0.422\right)$.

\subsubsection{Comparative statics}

Figures 2 and 3 show how the steady state equilibrium is affected by the two main policy parameters, $F$ and $\delta$, and also how these policies interact with the arrival rate $\lambda$ of idiosyncratic shocks. Moving left to right, dots differ by $10 \%$; the graphs show the effects of changing $F$ and $\delta$ by $\pm 30 \%$ around their baseline levels. Changes in $\lambda$ range from $-20 \%$ (blue) to $+20 \%$ (magenta); red dots represent the baseline value of $\lambda$.

Several aspects of Figure 2 illustrate the "sclerotic" effects of increased firing costs, which slow down labor market flows, but have an ambiguous effect overall on the unemployment rate. In the second row, we see that $R^{P}$ decreases with $F$, whereas $R^{C}$ increases - firms are less willing to fire permanent workers when firing costs are

\footnotetext{
${ }^{12}$ Notice that, given the latter four steady state values, the other two transition probabilities in our model (temporary employment to unemployment and to permanent employment, respectively) are pinned down by the steady state laws of motion in our model.
} 

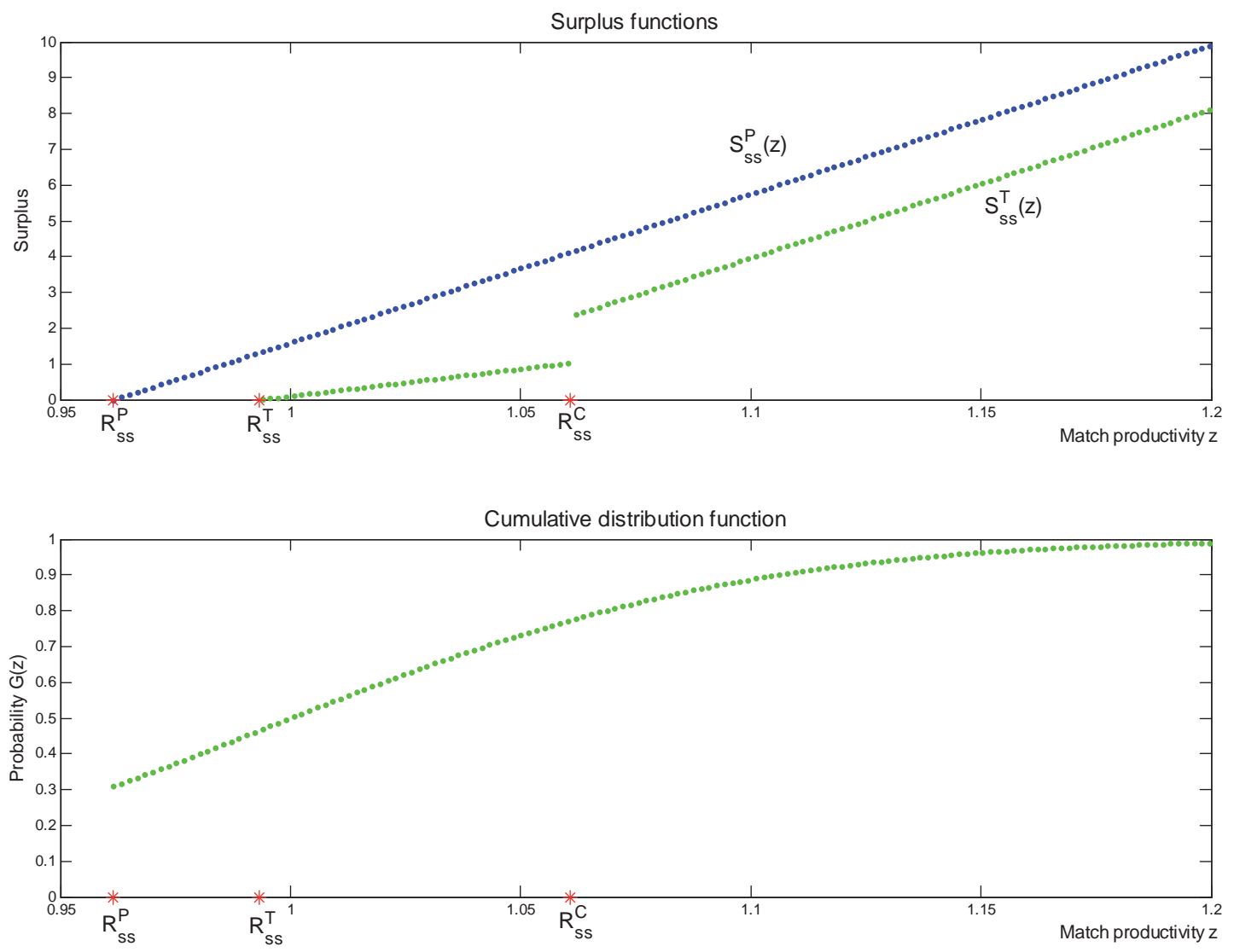

Figure 1: Steady state: surplus functions and distribution function

high, but they are also less willing to promote them to permanence. Therefore the overall flow into and out of permanent jobs is much slower when $F$ is large. Sclerosis can also be seen in the effect on $q(\theta)$ : higher firing costs lower vacancy formation and labor market tightness (and hence $q(\theta)$ increases).

On the other hand, since higher firing costs make firms less willing to contract permanent workers, they also become less selective about which temporary workers they hire. Therefore $R^{T}$ decreases with $F$. This effect is strong enough so that unemployed workers' probability of reemployment, $p(\theta)\left(1-G\left(R^{T}\right)\right)$, rises even as workers' matching probability $p(\theta)$ falls. Thus, the flip side of greater "sclerosis" of permanent jobs is greater "churning" of temporary jobs, as both the rate of creation and destruction of temporary jobs increases with $F$.

The overall result, at the baseline calibration of $\lambda$, is that changing $F$ has little 

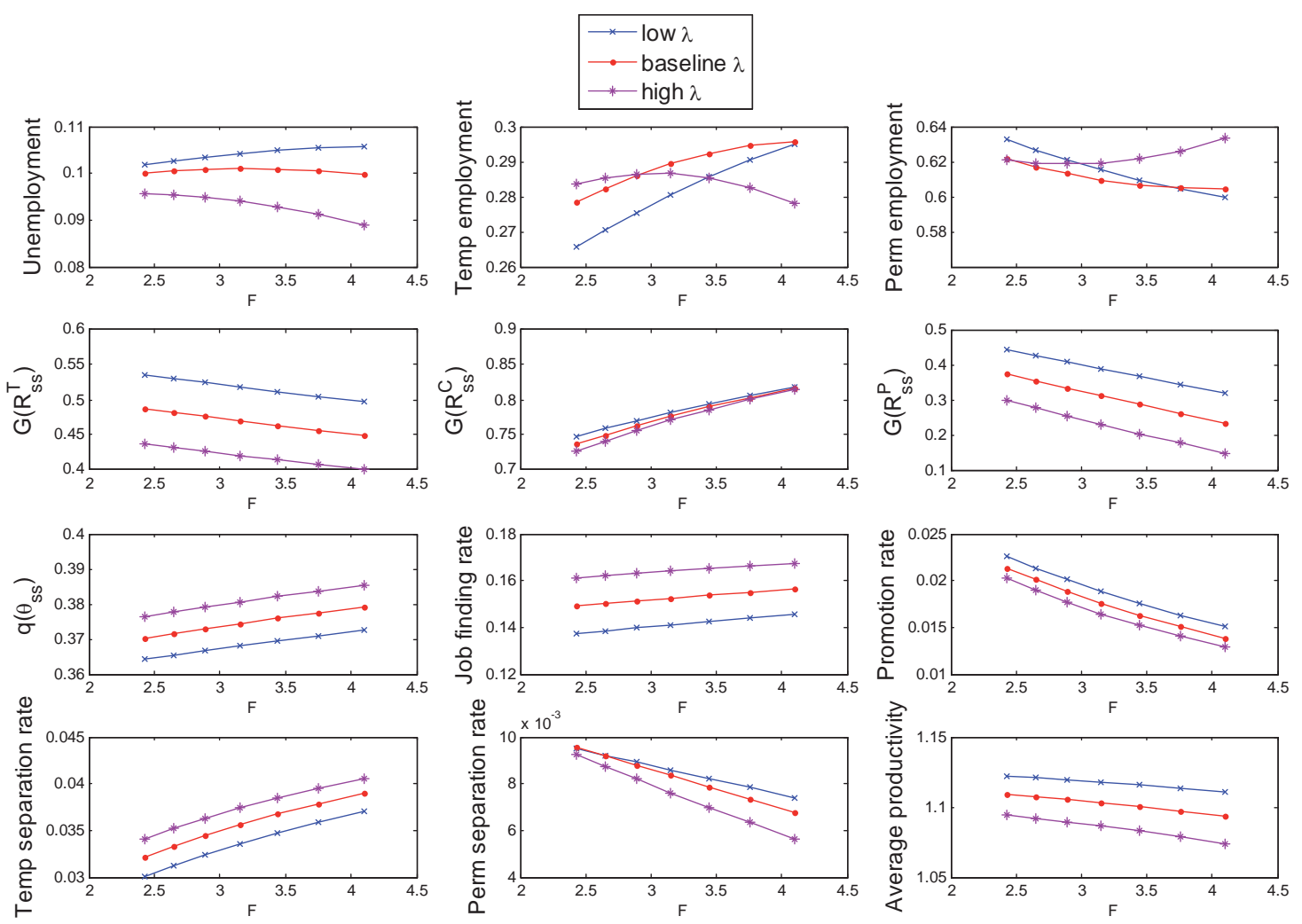

Figure 2: Comparative statics: firing cost

effect on unemployment. However, with lower $\lambda$ (blue dots), higher firing costs raise unemployment, as an increasing fraction of total employment is shifted into temporary contracts with little prospect of eventual promotion. At the opposite extreme, with a higher $\lambda$, the current value of idiosyncratic productivity is less important, making firms less selective about all contract types. In particular, with high $\lambda$ the fraction of permanent workers fired after an idiosyncratic shock falls from $30 \%$ to $15 \%$ as $F$ rises, so in this case unemployment decreases with $F$.

While firing costs have an ambiguous effect on unemployment, over this parameter range they unambiguously reduce productivity, as the last panel of Figure 2 shows. Intuitively, while firing costs make firms more selective about which matches to promote, they also makes firms less selective about the permanent workers they retain, and prompts them to rely more on rapid hiring and firing of relatively lowproductivity temporary workers. Thus while an increase in $F$ implies that those 

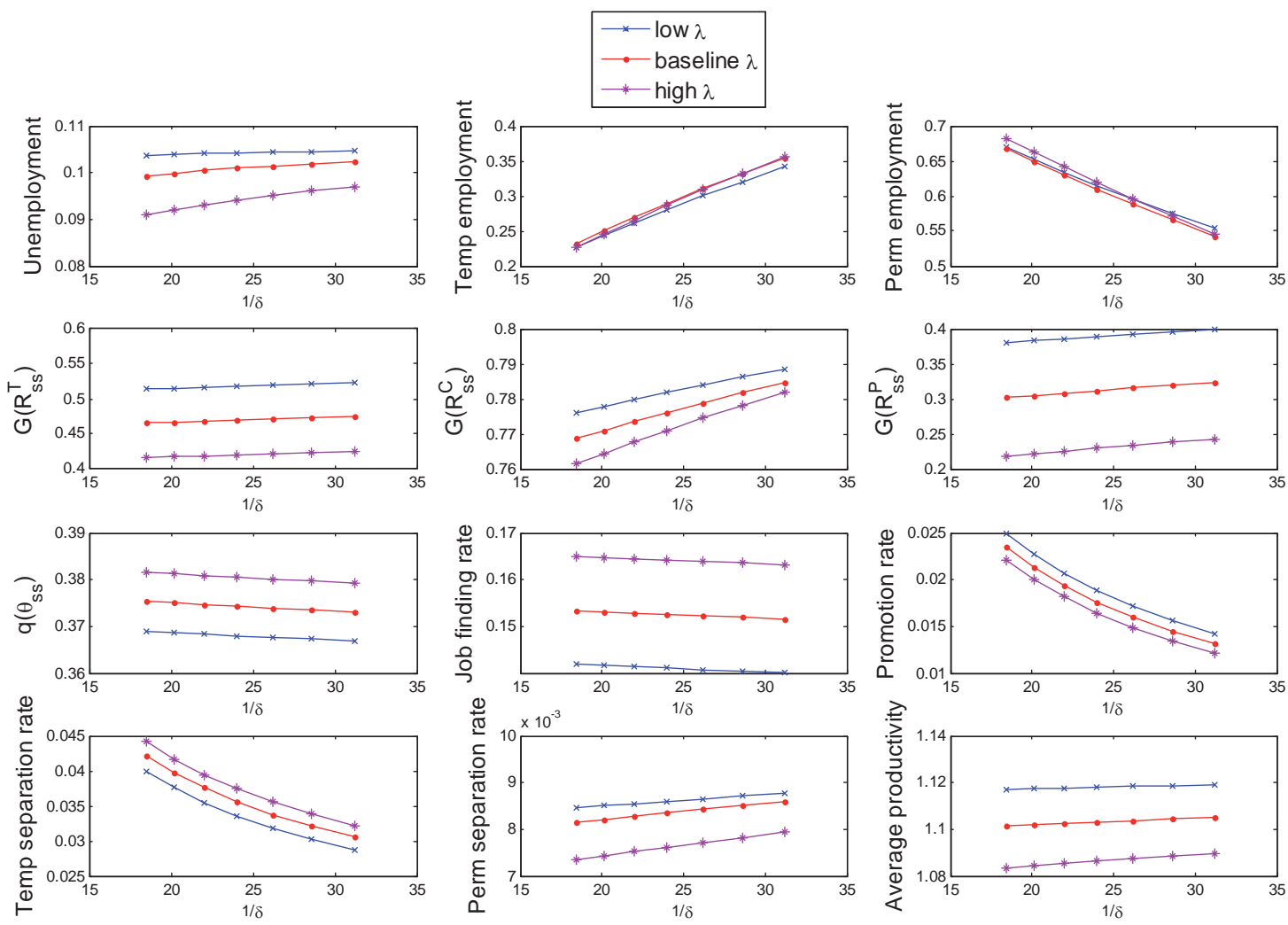

Figure 3: Comparative statics: temporary contract duration

workers who have just been promoted to permanence will have higher productivity, it also implies that temporary workers and old permanent workers will have lower productivity. For all the $\lambda$ values shown in Figure 2, the overall effect is roughly a $1 \%$ fall in average worker productivity as we increase $F$ by $60 \%$.

Figure 3 shows the effects of the duration $1 / \delta$ of temporary contracts, interacted as before with the arrival rate $\lambda$ of idiosyncratic shocks. An increase in $1 / \delta$ makes firms moderately more selective at all the reservation thresholds, so productivity rises. But in terms of employment, the main impact is the direct one: as temporary contracts expire more slowly, they are a sharply increasing fraction of the labor force. The rate of separation of temporary workers falls, while the firing rate of permanent workers increases and the fraction of expired temporary contracts promoted to permanence decreases. Thus, increasing $1 / \delta$ causes firms to rely more on their temporary workforce instead of promotion to permanence. This shift in favor 
of shorter-lived employment increases the unemployment rate (as in Blanchard and Landier, 2002), though the effect is small except when $\lambda$ is high.

\section{Dynamics}

\subsection{Value and surplus functions}

Next, we study dynamic equilibrium in the presence of aggregate shocks. In the steady state analysis of Section 3, the Bellman equations contained capital gains terms associated with idiosyncratic shocks arriving at rate $\lambda$. Now, they also contain capital gains from aggregate shocks at rate $\mu$. The value functions for temporary and permanent jobs satisfy

$$
\begin{gathered}
(r+\rho) J^{T}(z, y)=z+y-w_{T}(z, y)+\delta\left[\mathbf{1}\left(z \geq R^{C}(y)\right) J^{P}(z, y)-J^{T}(z, y)\right] \\
+\lambda\left[\int_{R^{T}(y)} J^{T}(x, y) d G(x)-J^{T}(z, y)\right]+\mu\left[\sum_{y^{\prime}: R^{T}\left(y^{\prime}\right) \leq z} M_{y^{\prime} \mid y} J^{T}\left(z, y^{\prime}\right)-J^{T}(z, y)\right], \\
(r+\rho) J^{P}(z, y)=z+y-w_{P}(z, y)+\lambda\left[\int_{R^{P}(y)} J^{P}(x, y) d G(x)-G\left(R^{P}(y)\right) F-J^{P}(z, y)\right] \\
+\mu\left[\sum_{y^{\prime}: R^{P}\left(y^{\prime}\right) \leq z} M_{y^{\prime} \mid y} J^{P}\left(z, y^{\prime}\right)-\sum_{y^{\prime}: R^{P}\left(y^{\prime}\right)>z} M_{y^{\prime} \mid y} F-J^{P}(z, y)\right] .
\end{gathered}
$$

A worker's value of employment under a temporary contract is determined by

$$
\begin{array}{r}
(r+\rho) W^{T}(z, y)=w_{T}(z, y)+\delta\left[\mathbf{1}\left(z \geq R^{C}(y)\right) W^{P}(z, y)+\mathbf{1}\left(z<R^{C}(y)\right) U-W^{T}(z, y)\right] \\
+\lambda\left[\int_{R^{T}(y)} W^{T}(x, y) d G(x)+G\left(R^{T}(y)\right) U(y)-W^{T}(z, y)\right] \\
+\mu\left[\sum_{y^{\prime}: R^{T}\left(y^{\prime}\right) \leq z} M_{y^{\prime} \mid y} W^{T}\left(z, y^{\prime}\right)+\sum_{y^{\prime}: R^{T}\left(y^{\prime}\right)>z} M_{y^{\prime} \mid y} U\left(y^{\prime}\right)-W^{T}(z, y)\right]
\end{array}
$$


where

$$
\begin{aligned}
(r+\rho) W^{P}(z, y)= & w_{P}(z, y)+\lambda\left[\int_{R^{P}(y)} W^{P}(x, y) d G(x)+G\left(R^{P}(y)\right) U(y)-W^{P}(z, y)\right] \\
& +\mu\left[\sum_{y^{\prime}: R^{P}\left(y^{\prime}\right) \leq z} M_{y^{\prime} \mid y} W^{P}\left(z, y^{\prime}\right)+\sum_{y^{\prime}: R^{P}\left(y^{\prime}\right)>z} M_{y^{\prime} \mid y} U\left(y^{\prime}\right)-W^{P}(z, y)\right]
\end{aligned}
$$

is the Bellman equation for the value employment under a permanent contract, and $(r+\rho) U(y)=b+p(\theta(y)) \int_{R^{T}(y)}^{\infty}\left(W^{T}(x, y)-U(y)\right) d G(x)+\mu \sum_{y^{\prime}} M_{y^{\prime} \mid y}\left(U\left(y^{\prime}\right)-U(y)\right)$

determines the value of unemployment.

By combining workers' and firms' Bellman equations like we did for the steady state model, we can now restate the Bellman equations in terms of total match surplus only. In analogy with equation (9), at all $z \geq R^{T}(y)$ the total match surplus for temporary jobs satisfies

$$
\begin{gathered}
(r+\rho+\lambda+\delta+\mu) S^{T}(z, y)=z+y-b-\frac{\eta c \theta(y)}{1-\eta}+\delta \mathbf{1}\left(z \geq R^{C}(y)\right)\left(S^{P}(z, y)-F\right) \\
+\lambda \int_{R^{T}(y)} S^{T}(x, y) d G(x)+\mu \sum_{y^{\prime}: R^{T}\left(y^{\prime}\right) \leq z} M_{y^{\prime} \mid y} S^{T}\left(z, y^{\prime}\right) .
\end{gathered}
$$

Likewise, at all $z \geq R^{P}(y)$ the surplus for permanent jobs satisfies

$$
\begin{aligned}
& (r+\rho+\lambda+\mu) S^{P}(z, y)=z+y-b+(r+\rho) F-\frac{\eta c \theta(y)}{1-\eta} \\
& +\lambda \int_{R^{P}(y)} S^{P}(x, y) d G(x)+\mu \sum_{y^{\prime}: R^{P}\left(y^{\prime}\right) \leq z} M_{y^{\prime} \mid y} S^{P}\left(z, y^{\prime}\right) .
\end{aligned}
$$

\subsection{Calculating the surplus functions: $N=2$ with large $F$}

As in the steady state case, Bellman equations (17)-(18) show that the surplus functions are piecewise linear, allowing us to calculate them explicitly if the reservation thresholds are given. Here, we calculate the surplus functions in the special case of two aggregate states: recessions, with aggregate productivity $y_{1}$, and booms, with aggregate productivity $y_{2}$. (The $N$-state case is similar, but requires more notation, so it is left for Appendix 1.) The transition matrix simplifies to

$$
M=\left(\begin{array}{ll}
M_{y_{1} \mid y_{1}} & M_{y_{1} \mid y_{2}} \\
M_{y_{2} \mid y_{1}} & M_{y_{2} \mid y_{2}}
\end{array}\right)
$$


Given the abbreviation $\mu_{j \mid i} \equiv \mu M_{y_{j} \mid y_{i}}$, and letting $-i$ indicate the state that is not state $i$, we have $\mu_{1 \mid 1}+\mu_{2 \mid 1}=\mu_{1 \mid 2}+\mu_{2 \mid 2}=\mu_{i \mid i}+\mu_{-i \mid i}=\mu$.

With two states, there are six relevant productivity cutoffs, three for recessions: $R_{1}^{P} \leq R_{1}^{T} \leq R_{1}^{C}$, and three for booms: $R_{2}^{P} \leq R_{2}^{T} \leq R_{2}^{C}$. We also know that $R_{2}^{i} \leq R_{1}^{i}$ for $i \in\{T, C, P\}$. Furthermore, for the Spanish case that motivates us, firing costs are large. Therefore we will analyze an equilibrium in which $F$ is large enough compared to $y_{2}-y_{1}$ so that $R_{1}^{C}$ and $R_{2}^{C}$ are both greater than $R_{1}^{T}$ and $R_{2}^{T}$, which in turn are greater than $R_{1}^{P}$ and $R_{2}^{P}$. This orders all the thresholds; it now helps to define the notation $r_{7} \equiv 0, r_{6} \equiv R_{2}^{P}, r_{5} \equiv R_{1}^{P}, r_{4} \equiv R_{2}^{T}, r_{3} \equiv R_{1}^{T}, r_{2} \equiv R_{2}^{C}$, $r_{1} \equiv R_{1}^{C}$, and $r_{0} \equiv \infty$. We thus find seven relevant productivity intervals, of the form $I_{j} \equiv\left[r_{j}, r_{j-1}\right)$; all matches separate in interval $I_{7}$, whereas all continue in interval $I_{1}$.

For $N=2$, Bellman equation (18) can be simplified slightly by cancelling $\bar{\mu}_{i \mid i} S^{P}\left(z, y_{i}\right)$ from both sides, leaving

$$
\begin{aligned}
\left(r+\rho+\lambda+\mu_{-i \mid i}\right) S^{P}\left(z, y_{i}\right)= & z+y_{i}-b+(r+\rho) F-\frac{\eta c \theta\left(y_{i}\right)}{1-\eta} \\
& +\lambda \int_{R_{i}^{P}} S^{P}\left(x, y_{i}\right) d G(x)+\mu_{-i \mid i} \mathbf{1}\left(R_{-i}^{P} \leq z\right) S^{P}\left(z, y_{-i}\right)
\end{aligned}
$$

As in Section 3.2, we can now inspect (19) to see how $S^{P}(z, y)$ varies with $z$. First, note that (19) has no discontinuities. While the right-hand side seems to show a discontinuity at $z=R_{-i}^{P}$, the discontinuity vanishes because $S^{P}\left(R_{-i}^{P}, y_{-i}\right)=0$ in equilibrium. We therefore conclude that $S^{P}(z, y)$ is a continuous function.

Differentiating (19) with respect to $z$, the slope of $S^{P}$ in recessions and booms satisfies

$$
\left(r+\rho+\lambda+\mu_{-i \mid i}\right) \sigma_{i}^{P}=1+\mu_{-i \mid i} \mathbf{1}\left(R_{-i}^{P} \leq z\right) \sigma_{-i}^{P}
$$

where we have used the shorthand $\sigma_{i}^{P} \equiv \frac{\partial S^{P}}{\partial z}\left(z, y_{i}\right)$. Evidently, $S^{P}$ is piecewise linear. Using the fact that $R_{2}^{P}<R_{1}^{P}$, the slopes in different intervals are:

\begin{tabular}{|c|c|c|}
\hline & $R_{2}^{P}<z<R_{1}^{P}$ & $R_{1}^{P}<z$ \\
\hline \hline$\sigma_{1}^{P}$ & n.a. & $(r+\rho+\lambda)^{-1}$ \\
\hline$\sigma_{2}^{P}$ & $\left(r+\rho+\lambda+\mu_{1 \mid 2}\right)^{-1}$ & $(r+\rho+\lambda)^{-1}$ \\
\hline
\end{tabular}

Finally, using $S^{P}\left(R_{1}^{P}, y_{1}\right)=S^{P}\left(R_{2}^{P}, y_{2}\right)=0$, the surplus function for permanent jobs 
can be written explicitly in terms of the reservation productivities as

$$
\begin{aligned}
& S^{P}\left(z, y_{1}\right)=\frac{1}{r+\rho+\lambda}\left(z-R_{1}^{P}\right) \\
& S^{P}\left(z, y_{2}\right)= \begin{cases}\frac{1}{r+\rho+\lambda+\mu_{1 \mid 2}}\left(z-R_{2}^{P}\right), & R_{2}^{P} \leq z \leq R_{1}^{P} \\
S^{P}\left(R_{1}^{P}, y_{2}\right)+\frac{1}{r+\rho+\lambda}\left(z-R_{1}^{P}\right), & R_{1}^{P}<z\end{cases}
\end{aligned}
$$

The procedure to calculate the surplus function for temporary workers is similar, but has a few more steps. We have assumed $F$ is sufficiently large compared to $y_{2}-y_{1}$ so that the two promotion thresholds $R_{2}^{C}$ and $R_{1}^{C}$ are both strictly greater than all the other thresholds. Thus (17) implies that $S^{T}\left(z, y_{1}\right)$ and $S^{T}\left(z, y_{2}\right)$ are both discontinuous both at $R_{2}^{C}$ and at $R_{1}^{C}$. We write these jumps as

$$
\Delta\left(R_{j}^{C}, y_{i}\right) \equiv \lim _{d z \rightarrow 0}\left[S^{T}\left(R_{j}^{C}+d z, y\right)-S^{T}\left(R_{j}^{C}-d z, y\right)\right]
$$

This limit is well-defined because $S^{P}\left(z, y_{i}\right)-F=\frac{\eta}{1-\eta} F$ at $z=R_{i}^{C}$, and because all the $T$-thresholds are below all the $C$-thresholds. Simplifying as before by cancelling $\mu_{i \mid i} S^{T}\left(z, y_{i}\right)$ from both sides of (17), we obtain the following formula for the jumps at $R_{i}^{C}$ :

$$
\left(r+\rho+\lambda+\delta+\mu_{-i \mid i}\right) \Delta\left(R_{j}^{C}, y_{i}\right)=\delta \mathbf{1}\left(R_{j}^{C}=R_{i}^{C}\right) \frac{\eta}{1-\eta} F+\mu_{-i \mid i} \Delta\left(R_{j}^{C}, y_{-i}\right)
$$

These are four equations to determine the jumps $\Delta\left(R_{1}^{C}, y_{1}\right), \Delta\left(R_{1}^{C}, y_{2}\right), \Delta\left(R_{2}^{C}, y_{1}\right)$, and $\Delta\left(R_{2}^{C}, y_{2}\right)$. The solution is:

\begin{tabular}{|c|c|c|}
\hline & at $z=R_{2}^{C}$ & at $z=R_{1}^{C}$ \\
\hline \hline$\Delta\left(z, y_{1}\right)$ & $\mu_{2 \mid 1} \varepsilon F$ & $\left(r+\rho+\lambda+\delta+\mu_{1 \mid 2}\right) \varepsilon F$ \\
\hline$\Delta\left(z, y_{2}\right)$ & $\left(r+\rho+\lambda+\delta+\mu_{2 \mid 1}\right) \varepsilon F$ & $\mu_{1 \mid 2} \varepsilon F$ \\
\hline
\end{tabular}

where $\varepsilon=(r+\rho+\lambda+\delta)^{-1}\left(r+\rho+\lambda+\delta+\mu_{1 \mid 2}+\mu_{2 \mid 1}\right)^{-1} \frac{\delta \eta}{1-\eta}$.

We now turn to the slopes of $S^{T}(z, y)$. Using (17), and defining $\sigma_{i}^{T} \equiv \frac{\partial S^{T}}{\partial z}\left(z, y_{i}\right)$, we have

$$
\left(r+\rho+\lambda+\delta+\mu_{-i \mid i}\right) \sigma_{i}^{T}=1+\delta \mathbf{1}\left(z \geq R_{i}^{C}\right) \sigma_{i}^{P}+\mu_{-i \mid i} \mathbf{1}\left(R_{-i}^{T} \leq z\right) \sigma_{-i}^{T}
$$

We see that the slopes change at the points $R_{2}^{T}<R_{1}^{T}<R_{2}^{C}<R_{1}^{C}$. Solving each of this pair of equations (for $i=1,2$ ) equations on each relevant interval, we can summarize the slopes as follows:

\begin{tabular}{|c|c|c|c|c|}
\hline & $R_{2}^{T}<z<R_{1}^{T}$ & $R_{1}^{T}<z<R_{2}^{C}$ & $R_{2}^{C}<z<R_{1}^{C}$ & $R_{1}^{C}<z$ \\
\hline \hline$\sigma_{1}^{T}$ & n.a. & $(r+\rho+\lambda+\delta)^{-1}$ & $\frac{\omega_{1}}{r+\rho+\delta+\lambda}+\frac{1-\omega_{1}}{r+\rho+\lambda}$ & $(r+\rho+\lambda)^{-1}$ \\
\hline$\sigma_{2}^{T}$ & $\left(r+\rho+\lambda+\delta+\mu_{1 \mid 2}\right)^{-1}$ & $(r+\rho+\lambda+\delta)^{-1}$ & $\frac{\omega_{2}}{r+\rho+\delta+\lambda}+\frac{1-\omega_{2}}{r+\rho+\lambda}$ & $(r+\rho+\lambda)^{-1}$ \\
\hline
\end{tabular}


Here we have defined the weights $\omega_{1} \equiv \frac{r+\rho+\delta+\lambda+\mu_{1 \mid 2}}{r+\rho+\delta+\lambda+\mu_{1 \mid 2}+\mu_{2 \mid 1}}$ and $\omega_{2} \equiv \frac{\mu_{1 \mid 2}}{r+\rho+\delta+\lambda+\mu_{1 \mid 2}+\mu_{2 \mid 1}}$. Note that the slope of $S^{T}$ increases with $z$ (since $\omega_{2}<\omega_{1}$, we find that $\sigma_{1}^{T}<\sigma_{2}^{T}$ on interval $I_{2}$ ).

We can now write down an explicit formula for the surplus function for temporary jobs. Since $S^{T}$ is discontinuous at some points, it helps to define the notation

$$
S_{*}^{T}(z, y) \equiv \lim _{x \uparrow z} S^{T}(x, y)
$$

that is, the limit of the surplus function as we approach the point $z$ from below. This notation will help us see where the surplus functions are discontinuous, and how large the jumps are. Taking as given the reservation productivities, the surplus from a temporary job is given by

$$
\begin{aligned}
& S^{T}\left(z, y_{1}\right)= \begin{cases}\frac{1}{r+\rho+\delta+\lambda}\left(z-R_{1}^{T}\right), & R_{1}^{T} \leq z<R_{2}^{C} \\
S_{*}^{T}\left(R_{2}^{C}, y_{1}\right)+\mu_{2 \mid 1} \varepsilon F+\left(\frac{\omega_{1}}{r+\rho+\delta+\lambda}+\frac{1-\omega_{1}}{r+\rho+\lambda}\right)\left(z-R_{2}^{C}\right), & R_{2}^{C} \leq z<R_{1}^{C} \\
S_{*}^{T}\left(R_{1}^{C}, y_{1}\right)+\left(r+\rho+\lambda+\delta+\mu_{1 \mid 2}\right) \varepsilon F+\frac{1}{r+\rho+\lambda}\left(z-R_{1}^{C}\right), & z \geq R_{1}^{C},\end{cases} \\
& S^{T}\left(z, y_{2}\right)= \begin{cases}\frac{1}{r+\rho+\delta+\lambda+\mu_{12}}\left(z-R_{2}^{T}\right), & R_{2}^{T} \leq z<R_{1}^{T} \\
S^{T}\left(R_{1}^{T}, y_{2}\right)+\frac{1}{r+\rho+\delta+\lambda}\left(z-R_{1}^{T}\right), & R_{1}^{T} \leq z<R_{2}^{C} \\
S_{*}^{T}\left(R_{2}^{C}, y_{2}\right)+\left(r+\rho+\lambda+\delta+\mu_{2 \mid 1}\right) \varepsilon F+\left(\frac{\omega_{2}}{r+\rho+\delta+\lambda}+\frac{1-\omega_{2}}{r+\rho+\lambda}\right)\left(z-R_{2}^{C}\right), & R_{2}^{C} \leq z<R_{1}^{C} \\
S_{*}^{T}\left(R_{1}^{C}, y_{2}\right)+\mu_{1 \mid 2} \varepsilon F+\frac{1}{r+\rho+\lambda}\left(z-R_{1}^{C}\right), & z \geq R_{1}^{C} .\end{cases}
\end{aligned}
$$

Figure 4 shows the dynamic surplus functions (20a)-(20b) and (21)-(22), in equilibrium under our benchmark parameterization. Like the steady state surplus functions, they are piecewise linear with discountinuities in $S^{T}$ at thresholds $R_{2}^{C}$ and $R_{1}^{C}$. Now, though, we see four functions, since we are plotting both for recessions and booms; from top to bottom the functions are $S^{P}\left(z, y_{2}\right), S^{P}\left(z, y_{1}\right), S^{T}\left(z, y_{2}\right)$, and $S^{P}\left(z, y_{1}\right)$. The top two and the bottom two each lie close together, because the difference in surplus between recessions and booms is much smaller than the difference in surplus between temporary and permanent employment status.

Red stars indicate the six reservation thresholds (from left to right) $R_{2}^{P}, R_{1}^{P}, R_{2}^{T}$, $R_{1}^{T}, R_{2}^{C}$, and $R_{1}^{C}$. One effect of passing from boom to recession is the immediate firing of all permanent workers with productivity in the interval $I_{6}=\left[R_{2}^{P}, R_{1}^{P}\right)$, and all temporary workers with productivity in the interval $I_{4}=\left[R_{2}^{T}, R_{1}^{T}\right)$; then when the economy returns to its expansive phase, new stocks of these "fragile" jobs gradually build up. The size of the wave of firing that occurs at the beginning of a recession depends on the buildup of employment in these intervals of fragility, which in turn depends on the duration of the preceding boom. 


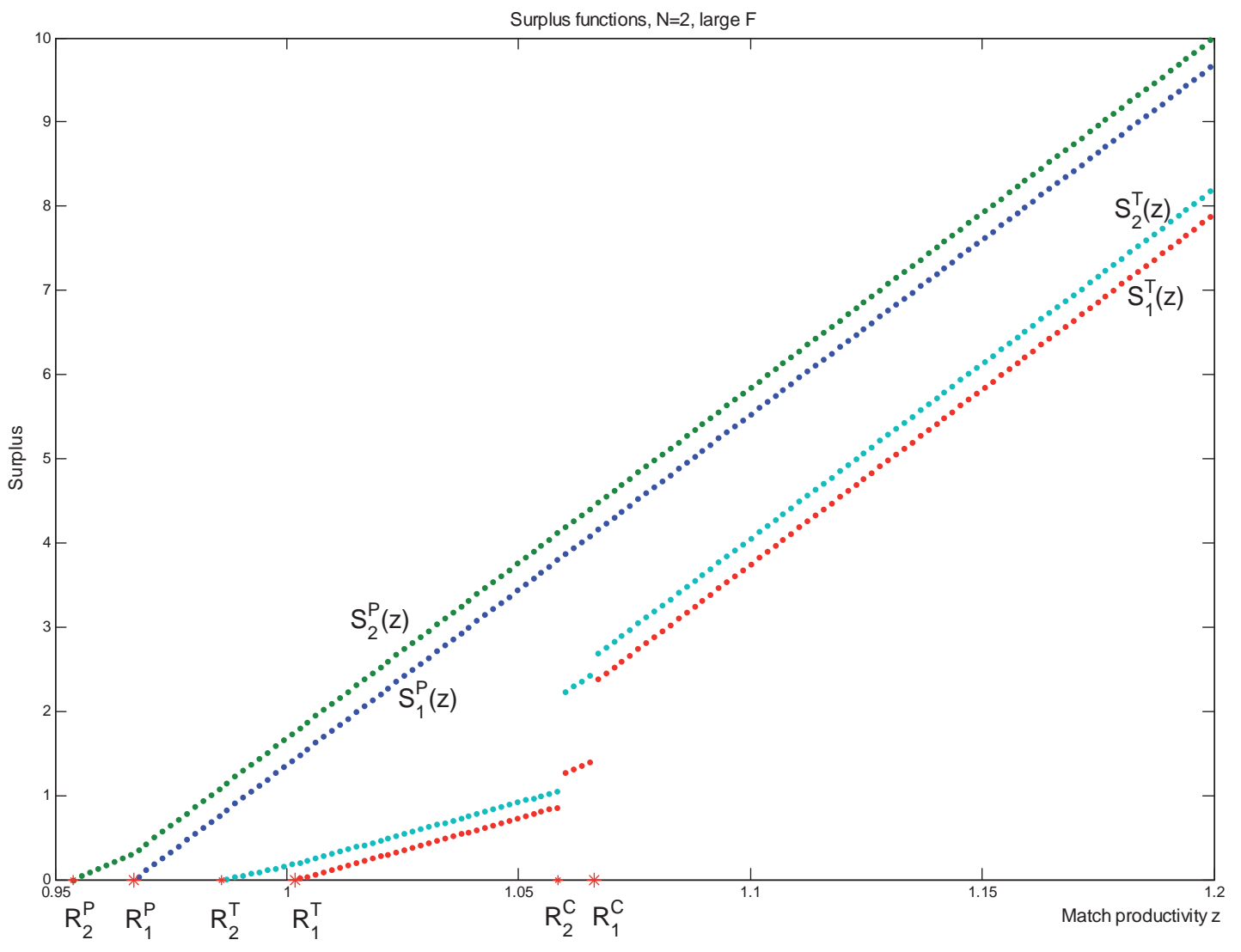

Figure 4: Dynamic surplus functions

\subsection{Dynamic equilibrium}

The job creation and destruction conditions of the dynamic model are similar to the steady state equations (13)-(16), except that now the equations must hold for each aggregate state $y_{i}$, for $i \in\{1,2, \ldots, N\}$. The job creation condition is

$$
\frac{c}{q\left(\theta\left(y_{i}\right)\right)}=(1-\eta) \int_{R_{i}^{T}} S^{T}\left(x, y_{i}\right) d G(x)
$$

We now rewrite the job destruction conditions using the Bellman equations. The job destruction condition (6) for temporary jobs becomes

$$
0=R_{i}^{T}+y_{i}-b-\frac{\eta c \theta\left(y_{i}\right)}{1-\eta}+\lambda \int_{R_{i}^{T}} S^{T}\left(x, y_{i}\right) d G(x)+\mu \sum_{j: y_{j} \geq y_{i}} M_{y_{j} \mid y_{i}} S^{T}\left(R_{i}^{T}, y_{j}\right) .
$$


For permanent jobs, the job destruction condition (8) is

$0=R_{i}^{P}+y_{i}-b+(r+\rho) F-\frac{\eta c \theta\left(y_{i}\right)}{1-\eta}+\lambda \int_{R_{i}^{P}} S^{P}\left(x, y_{i}\right) d G(x)+\mu \sum_{j: y_{j} \geq y_{i}} M_{y_{j} \mid y_{i}} S^{P}\left(R_{i}^{P}, y_{j}\right)$.

Finally, the promotion threshold in state $y_{i}$ can be determined by:

$(r+\rho+\lambda+\mu) \frac{F}{1-\eta}=R_{i}^{C}+y_{i}-b+(r+\rho) F-\frac{\eta c \theta\left(y_{i}\right)}{1-\eta}+\lambda \int_{R_{i}^{P}} S^{P}\left(x, y_{i}\right) d G(x)+\mu \sum_{j: y_{j} \geq y_{i}} M_{y_{j} \mid y_{i}} S^{P}\left(R_{i}^{P}, y_{j}\right)$.

Given hypothetical values of $R^{P}(y), R^{C}(y)$, and $R^{T}(y)$, we can now use our surplus formulas to evaluate the right-hand side of (23)-(26) for each $y$. For $N=2$, this just means plugging in formulas (20a)-(20b) and (21)-(22). When $N>2$, we instead use the slope and jump formulas (36), (34), and (39), stated in Appendix 1, to numerically evaluate the surplus functions and integrals appearing in (23)-(26). The result is a system of $4 N$ equations to determine the $4 N$ unknowns $R^{P}(y), R^{C}(y)$, $R^{T}(y)$, and $\theta(y)$, which together describe a dynamic equilibrium.

\subsection{Employment and productivity dynamics}

Once $R^{P}(y), R^{C}(y), R^{T}(y)$, and $\theta(y)$ are known we can simulate employment over time by keeping track of temporary and permanent jobs on the productivity intervals $I_{j}=\left[r_{j}, r_{j-1}\right), j \in\{1,2, \ldots, 3 N\}$ in which employment may occur. First, let $n_{j}^{T}(t)$ be the stock of temporary matches with productivity $z$ in interval $I_{j}=\left[r_{j}, r_{j-1}\right)$. Second, define total temporary employment as $n^{T}(t)=\sum_{j=0}^{3 N} n_{j}^{T}(t)$. Next, let $n_{j}^{P}(t)$ and $n^{P}(t)=\sum_{j=0}^{3 N} n_{j}^{P}(t)$ be the corresponding stocks of permanent jobs. Finally, define unemployment as $u(t)=1-n^{T}(t)-n^{P}(t)$.

Over a short time interval $d t$, in which aggregate productivity is $y(t)$, employment of each type evolves according to

$$
\begin{gathered}
d n_{j}^{T}(t)=\left\{\begin{array}{cc}
-n_{j}^{T}(t) & \text { if } R^{T}(y(t+d t)) \geq r_{j-1} \\
{\left[p(\theta(y(t))) u(t)+\lambda n^{T}(t)\right]\left[G\left(r_{j-1}\right)-G\left(r_{j}\right)\right] d t-(\rho+\delta+\lambda) n_{j}^{T}(t) d t} & \text { otherwise } \\
-n_{j}^{P}(t) & \text { if } R^{P}(y(t+d t)) \geq r_{j-1}
\end{array}\right. \\
d n_{j}^{P}(t)=\left\{\begin{array}{ccc}
\left\{\lambda\left[G\left(r_{j-1}\right)-G\left(r_{j}\right)\right] n^{P}(t)+\delta n_{j}^{T}(t)\right\} d t-(\rho+\lambda) n_{j}^{P}(t) d t & \text { otherwise }
\end{array}\right.
\end{gathered}
$$

Equation (27) shows that the change in temporary employment in interval $I_{j}$, which we write as $d n_{j}^{T}(t)=n_{j}^{T}(t+d t)-n_{j}^{T}(t)$, can take two possible forms. If the aggregate 
state at $t+d t$ is bad enough so that $R^{T}(y(t+d t)) \geq r_{j-1}$, then all temporary jobs in interval $I_{j}$ (if any) will separate, and therefore $d n_{j}^{T}(t)=-n_{j}^{T}(t)$. Otherwise, employment accumulates gradually in interval $I_{j}$, so the flow $d n_{j}^{T}(t)$ is proportional to the time interval $d t$. Temporary employment flows into $I_{j}$ due to new hires, and also due to idiosyncratic shocks to existing temporary jobs; conditional on either of these events, the probability of falling into interval $I_{j}$ is $G\left(r_{j-1}\right)-G\left(r_{j}\right)$. We also see outflows of temporary employment from interval $I_{j}$ due to retirement (at rate $\rho$ ), contract expiry (at rate $\delta$ ), and idiosyncratic shocks (at rate $\lambda$ ).

The intuition of (28) is similar. Any permanent jobs existing in interval $I_{j}$ are fired immediately when the permanent firing threshold rises above $r_{j-1}$. Otherwise, jobs flow into the employment stock $n_{j}^{P}(t)$ either due idiosyncratic shocks to permanent jobs or due to expiry of temporary contracts in interval $I_{j}$; and they flow out of $n_{j}^{P}(t)$ due to retirement or as idiosyncratic shocks arrive.

\subsection{Solving for the wage}

We can also solve for equilibrium wages by combining the bargaining rules with the relevant Bellman equations. For temporary workers,

$$
w_{T}(z, y)=\eta[z+y+c \theta(y)-\delta F]+(1-\eta) b,
$$

if $z \geq R^{C}(y)$, and

$$
w_{T}(z, y)=\eta[z+y+c \theta(y)]+(1-\eta) b,
$$

otherwise. Notice that the wage of temporary workers decreases by $\eta \delta F$ at the threshold $R^{C}(y)$, because a worker with $z \geq R^{C}(y)$ expects his/her job to last longer, and therefore obtains more surplus through expected future payments instead of payments now. For permanent jobs, the wage equation is

$$
w_{P}(z, y)=\eta[z+y+c \theta(y)+(r+\rho) F]+(1-\eta) b .
$$

Notice that, conditional on the same level of productivity, the wage of permanent and temporary workers differ by the amount $\eta\left[(r+\rho)+\delta \mathbf{1}\left(z \geq R^{C}(y)\right)\right] F$. Therefore, firing costs introduce a wedge between the wages of both types.

\section{Dynamic results: $N=2$ with large $F$}

In this section, we study the business cycle dynamics of our model under the baseline parameterization, with two possible aggregate states. We begin by reporting some 


\begin{tabular}{|l|l|l|l|l|}
\hline Variable & \multicolumn{2}{|c|}{ Model } & \multicolumn{2}{c|}{ Model: conditional SS } \\
\hline Stocks & SS & Mean & Recession & Boom \\
$n^{T}$ & & & & \\
$n^{P}$ & $28.95 \%$ & $29.01 \%$ & $29.40 \%$ & $28.23 \%$ \\
$u$ & $100.96 \%$ & $59.45 \%$ & $58.18 \%$ & $63.03 \%$ \\
Probabilities & $10.09 \%$ & $11.54 \%$ & $12.42 \%$ & $8.73 \%$ \\
prob $(T \mid U)$ & $15.25 \%$ & $15.55 \%$ & $12.80 \%$ & $16.96 \%$ \\
prob $(P \mid T)$ & $1.76 \%$ & $1.70 \%$ & $1.76 \%$ & $1.71 \%$ \\
$\operatorname{prob}(U \mid T)$ & $3.35 \%$ & $3.36 \%$ & $3.44 \%$ & $3.33 \%$ \\
prob $(U \mid P)$ & $0.63 \%$ & $0.60 \%$ & $0.68 \%$ & $0.56 \%$ \\
Flows & & & & \\
JC & $1.54 \%$ & $1.44 \%$ & $1.59 \%$ & $1.48 \%$ \\
JD & $1.54 \%$ & $1.44 \%$ & $1.59 \%$ & $1.48 \%$ \\
\hline
\end{tabular}

Table 2: Average behavior of benchmark model. Monthly frequency, quantities expressed as \% of labor force

first moments in Table 2. Since the calibration is chosen for consistency with the average stocks of temporary and permanent workers in Spanish data $\left(n^{T}=0.2895\right.$ and $\left.n^{P}=0.6095\right)$, these are reproduced precisely by the steady state of the model. However, given the model's extreme nonlinearity, its steady state differs from the mean of its dynamics in the presence of aggregate shocks. In particular, unemployment is almost one and a half percentage points higher in the mean of the economy with aggregate productivity shocks than it is in the steady state. This happens because recessions initially cause unemployment to dramatically overshoot the "conditional steady state" towards which it converges while the recessionary state lasts. The last two columns of Table 2 show conditional steady states: we see that in the limit of an arbitrarily long recession, the unemployment rate exceeds $12 \%$, whereas in the limit of an arbitrarily long boom, it is less than $9 \%$. The mean unemployment rate over time is closer to the conditional steady state for recessions than it is to that for booms, since the time average includes the initial spikes occurring in recessions.

Thus, looking only at the conditional steady states implied by long recessions and booms is insufficient to characterize employment volatility in this economy. Instead, Table 3 reports second moments under several parameterizations. For clarity, we report volatilities both in levels (as a percentage of the labor force), and in logs. Overall, the model does quite a good job of reproducing observed Spanish labor 


\begin{tabular}{|l|l|l|l|l|}
\hline Data & \multicolumn{3}{|c|}{ Model } \\
\hline & Benchmark & 20\% lower F & 20\% lower $\delta$ & $10 \%$ lower $b$ \\
Stocks & & & & \\
$n_{s s}^{T}=28.95 \%$ & $28.95 \%$ & $27.98 \%$ & $34.49 \%$ & $24.74 \%$ \\
$n_{s s}^{P}=60.95 \%$ & $60.96 \%$ & $62.02 \%$ & $55.30 \%$ & $68.96 \%$ \\
$u_{s s}=10.10 \%$ & $10.09 \%$ & $10.00 \%$ & $10.21 \%$ & $6.30 \%$ \\
$s d\left(n^{T}\right)=1.13 \%$ & $0.74 \%$ & $0.73 \%$ & $0.82 \%$ & $0.44 \%$ \\
$s d\left(n^{P}\right)=0.58 \%$ & $0.65 \%$ & $0.69 \%$ & $0.59 \%$ & $0.51 \%$ \\
$s d(u)=0.90 \%$ & $1.08 \%$ & $1.10 \%$ & $1.11 \%$ & $0.64 \%$ \\
$F l o w s$ & & $4.49 \%$ & $4.65 \%$ & $3.87 \%$ \\
$J C_{s s}=J D_{s s}$ & $4.62 \%$ & $0.23 \%$ & $0.24 \%$ & $0.19 \%$ \\
$s d(J C)$ & $0.23 \%$ & $0.60 \%$ & $0.62 \%$ & $0.43 \%$ \\
$s d(J D)$ & $0.60 \%$ & \multicolumn{3}{|l}{} \\
\hline
\end{tabular}

Table 3: Effects of liberalizing labor market. Quarterly frequency, detrended HP1600, quantities expressed as \% of labor force.

market fluctuations, which are calculated from quarterly EPA data, 2001:1-2008:3. ${ }^{13}$ The coefficient of variation of unemployment in the model, $1.08 / 10.09=0.107$, slightly exceeds the coefficient of variation in the data, 0.092. Moreover, the relative volatility of the two labor market stocks in the model also fits the data quite well. In Table 2, looking just at conditional steady states, permanent contracts seemed more volatile than temporary contracts (and moreover, at the conditional steady state, temporary employment is countercyclical). But in Table 3, we see that temporary employment is more volatile than permanent employment, both in the model and in the data. In relative terms, temporary jobs are more than twice as volatile as permanent jobs. Moreover, temporary jobs account for a larger share of employment fluctuations than permanent jobs in absolute terms too, even though on average temporary employment is less than one third of the total.

The alternative parameterizations consider several reforms that would make the labor market more flexible. In the "lower $F$ " parameterization, we decrease the firing cost by $20 \%$. In the "lower $\delta$ " parameterization, we decrease $\delta$ by $20 \%$ (that is, we increase the duration of eligibility for a temporary contract by $20 \%$ ). These two policy changes have rather small effects. However, we already know that $F$ and $\delta$ have ambiguous effects on steady state employment (Bentolila and Bertola, 1990;

\footnotetext{
${ }^{13}$ Both the data and the simulations from the model are HP-filtered with parameter 1600 . Unfortunately our use of data classified by temporary/permanent status restricts us to a rather short sample.
} 

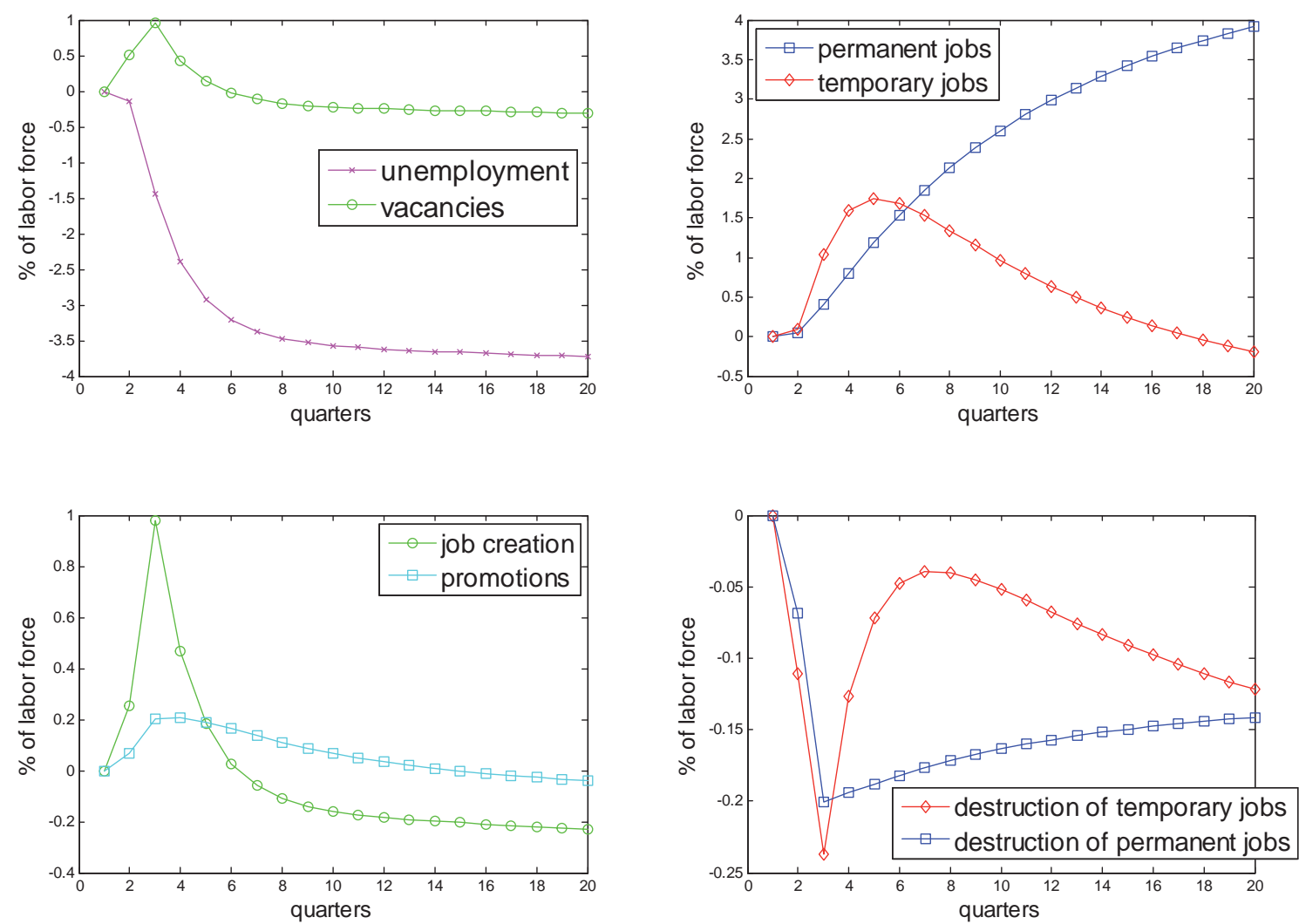

Figure 5: Impulse responses: recession to boom

Blanchard and Landier, 2002), so perhaps their relatively small effect on volatility should be unsurprising.

Finally, we also consider the effect of decreasing unemployment protection by $10 \%$ (i.e. by eight percentage points from $80 \%$ to $72 \%$ of average worker productivity). Costain and Reiter (2008) have argued that increasing the benefit level makes the match surplus smaller and more volatile, implying larger fluctuations in employment and unemployment. Here we see that this reform has a much more powerful effect than changes in $F$ or $\delta$; it causes a large decrease in steady state unemployment (from $10.1 \%$ to $6.3 \%$ ), as well as a large decrease in labor market volatility. Note that the decrease in volatility caused by a lower $b$ is especially pronounced in temporary jobs.

Next, to better understand the effects of dual labor market policy on employment volatility, Figures 5 and 6 show the impulse responses of various labor market stocks 

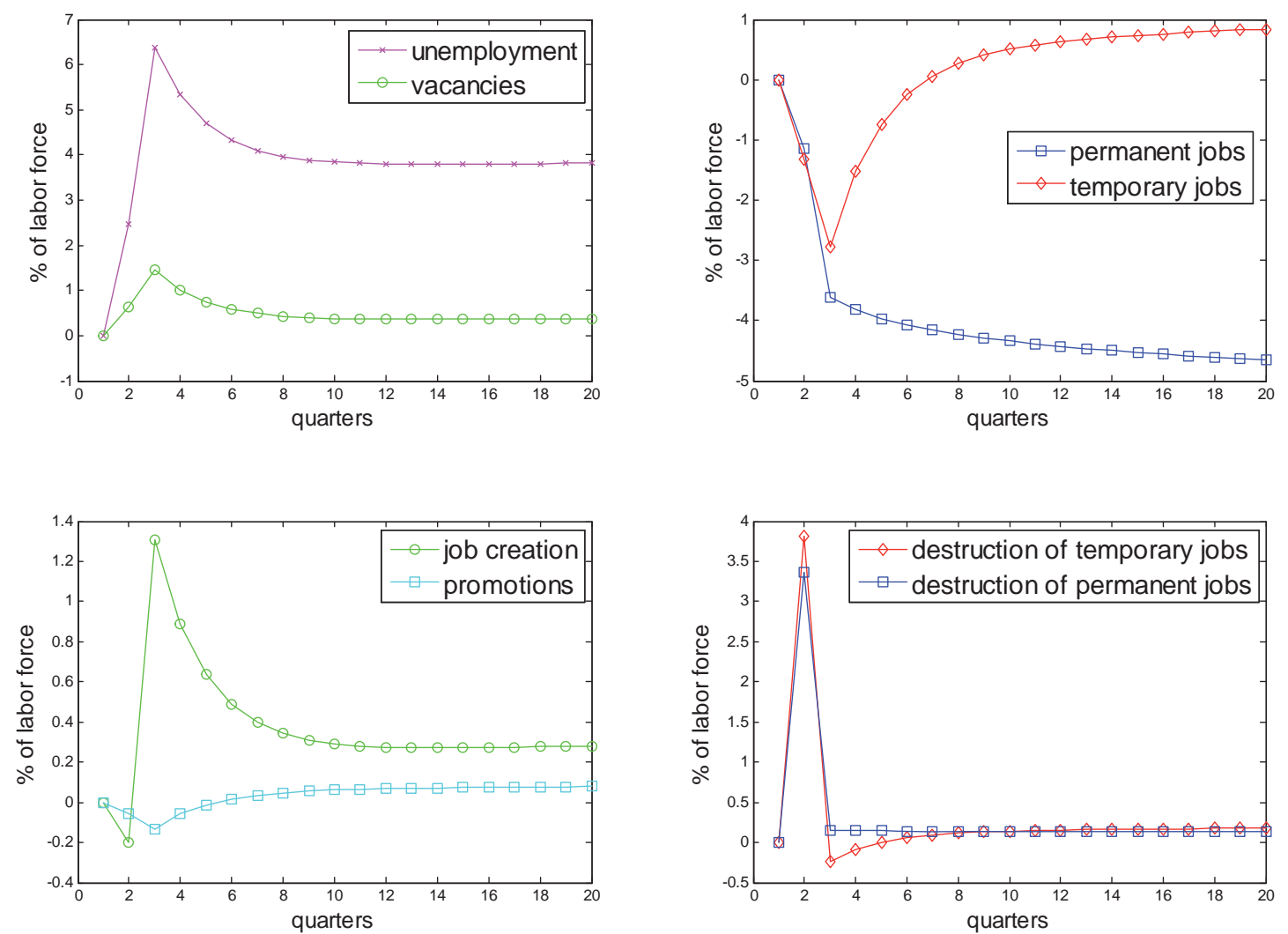

Figure 6: Impulse responses: boom to recession

and flows to an increase and a decrease in aggregate productivity (all variables are graphed as a percentage of the total labor force). We note that the nonlinearity of the model makes these responses extremely asymmetric. At the transition from recession to boom, there is a hump-shaped response of temporary jobs, as new workers are hired, passing initially through temporary status and then eventually building up a higher stock of permanent matches. At the same time, job destruction of each type of worker briefly decreases by 0.2 percent of the workforce. In contrast, at the transition from boom to recession, there is a sudden burst of firing, with more than $3 \%$ of the workforce fired in each contract type (a total of almost $7 \%$ of the workforce is fired at this time). Both stocks of workers fall, with the stock of temps recovering quickly while the stock of permanent workers gradually decreases towards a new, lower conditional steady state. 
The responses also depend on the starting point; the impulse responses shown here are calculated starting from the conditional steady state. In other words, Figure 5 is the effect of an increase in $y$ after an extremely long recession, and Figure 6 is the effect of a decrease in $y$ after an extremely long boom. Note that after an extremely long boom, a recession causes roughly equal levels of firing of temporary and permanent jobs. This seems to suggest that fluctuations in permanent jobs should be almost as important as fluctuations in temporary jobs to explain employment volatility overall.

However, such a conclusion would be mistaken, because the size of the burst in firing of temporary and permanent jobs at the beginning of a recession depends on the length of the preceding boom. The stock of permanent jobs builds up more slowly in a boom than the stock of temps, because workers must pass through temporary status before reaching permanent status, and because the productivity threshold for hiring is lower than the threshold for promotion. Therefore, mostly temporary jobs are fired after a short boom, whereas after a long boom a substantial number of permanent jobs separate too.

The differing ratios of temporary and permanent firing after expansions of different lengths can be seen quite clearly in Figure 7, which shows an example of the model's simulated dynamics over time. Note that since promotion and firing of permanent jobs are very slow processes, a boom must be very long to get anywhere near its "conditional steady state". Instead, given cycles of realistic length, relatively few "fragile" permanent jobs are accumulated in booms. Thus, after the first few booms shown in Figure 7, the red spike representing temporary firing is much larger than the blue spike representing firing of permanent jobs. Only in the exceptionally long boom seen in the second half of the simulated sample do we observe a spike of permanent firing comparable to the spike in temporary firing.

\subsection{Understanding the volatility of temporary employment}

Overall, then, as we already saw in Table 3, Figure 7 shows that temporary jobs play a much larger role for employment fluctuations than permanent jobs do. This is true both in relative terms and in absolute terms, in spite of the fact that the average stock of temps is roughly half that of permanent jobs. Several factors explain the high volatility of temporary jobs.

(A) Transitional role of temporary contracts. Given the institutional structure assumed here, matches pass through temporary status before achieving permanence. Therefore the rise in hiring associated with a boom leads initially to a rise in temporary employment. 

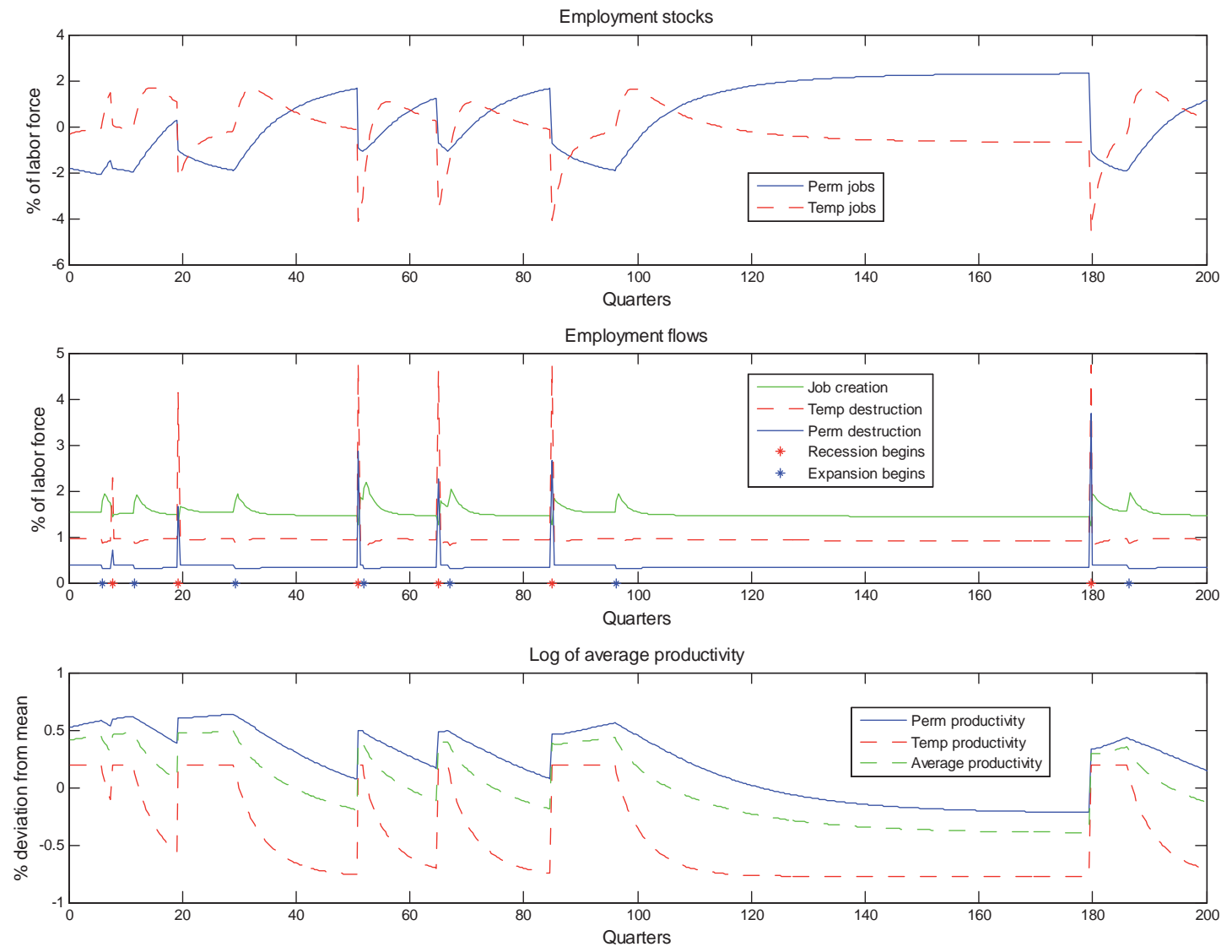

Figure 7: Example: dynamic simulation

As the stock of unemployed available for hiring decreases, temporary employment begins to fall back again. Thus the stock of temporary employment "overshoots" at the beginning of a boom.

This effect, caused by increased hiring in expansions, is important but still small compared with the effects of increased firing in recessions, which predominantly affect temps. To calculate the buildup of the "fragile" jobs - those vulnerable to firing as soon as the next recession arrives - we can evaluate equations (27) and (28) at the interval $I_{4}=\left[R_{2}^{T}, R_{1}^{T}\right)$ of fragile temporary jobs, and at the interval $I_{6}=\left[R_{2}^{P}, R_{1}^{P}\right)$ of fragile permanent jobs, respectively. In a boom, we have

$$
\frac{d n_{4}^{T}(t)}{d t}=\left[p\left(\theta\left(y_{2}\right)\right) u(t)+\lambda n^{T}(t)\right]\left[G\left(R_{1}^{T}\right)-G\left(R_{2}^{T}\right)\right]-(\rho+\delta+\lambda) n_{4}^{T}(t)
$$




$$
\frac{d n_{6}^{P}(t)}{d t}=\lambda\left[G\left(R_{1}^{P}\right)-G\left(R_{2}^{P}\right)\right] n^{P}(t)-(\rho+\lambda) n_{6}^{P}(t)
$$

The rate of accumulation in these intervals depends on the mass in each interval, namely $G\left(R_{1}^{T}\right)-G\left(R_{2}^{T}\right)$ or $G\left(R_{1}^{P}\right)-G\left(R_{2}^{P}\right)$, which implies the following two effects.

(B) Widths of the intervals $\left[R_{2}^{T}, R_{1}^{T}\right)$ and $\left[R_{2}^{P}, R_{1}^{P}\right)$. A close look at Figure 4 shows that $R_{1}^{T}-R_{2}^{T}>R_{1}^{P}-R_{2}^{P}$. Therefore, productivity draws would fall more frequently in the interval $\left[R_{2}^{T}, R_{1}^{T}\right)$ than in $\left[R_{2}^{P}, R_{1}^{P}\right)$ even if the distribution $G(z)$ were uniform across the two intervals. Note that the width of the interval of fragility is related to discounting: a given increase in productivity $d z$ is worth less in a temporary match than in a permanent match, insofar as a temporary match has a shorter expected duration. We conjecture that this discounting effect makes firms move along the temporary firing margin more elastically than they do along the permanent firing margin.

(C) Central position of $R^{T}$. For any $y, R^{T}(y)$ lies between the other two thresholds. In our example with a log normal distribution, this leads to a higher density $G^{\prime}(z)$ near the $R^{T}$ thresholds than near the others. Therefore, productivity draws would fall more frequently in the interval $\left[R_{2}^{T}, R_{1}^{T}\right)$ than in $\left[R_{2}^{P}, R_{1}^{P}\right)$ even if the latter were just as wide as the former.

While effects (B) and (C) are both present in our simulations, Figures 1 and 4 indicate that they are not very significant quantitatively. But there is also an important qualitative difference in the way "fragile" jobs accumulate in temporary contracts compared with permanent contracts. Equation (29) shows that some temporary jobs are hired into interval $I_{4}$ directly from unemployment. In contrast, notice that there is no $\delta$ term in equation (30). This is the most important difference in the dynamics of the two contract types: permanent jobs in the fragility interval $I_{6}$ are formed only through idiosyncratic shocks; new permanent jobs created due to expiry of temporary contracts instead fall into intervals $I_{1}$ or $I_{0}$, where jobs are not fragile.

(D) Hiring of fragile temporary workers. When created, permanent matches are all highly productive: they all have productivity exceeding $R^{C}(y)$. Therefore (assuming sufficiently large $F$, as in our simulations) no newly-created permanent matches are fragile. Permanent matches only become fragile when large idiosyncratic shocks move them into the interval $\left[R_{2}^{P}, R_{1}^{P}\right)$. In contrast, $R^{T}(y)$ acts both as 


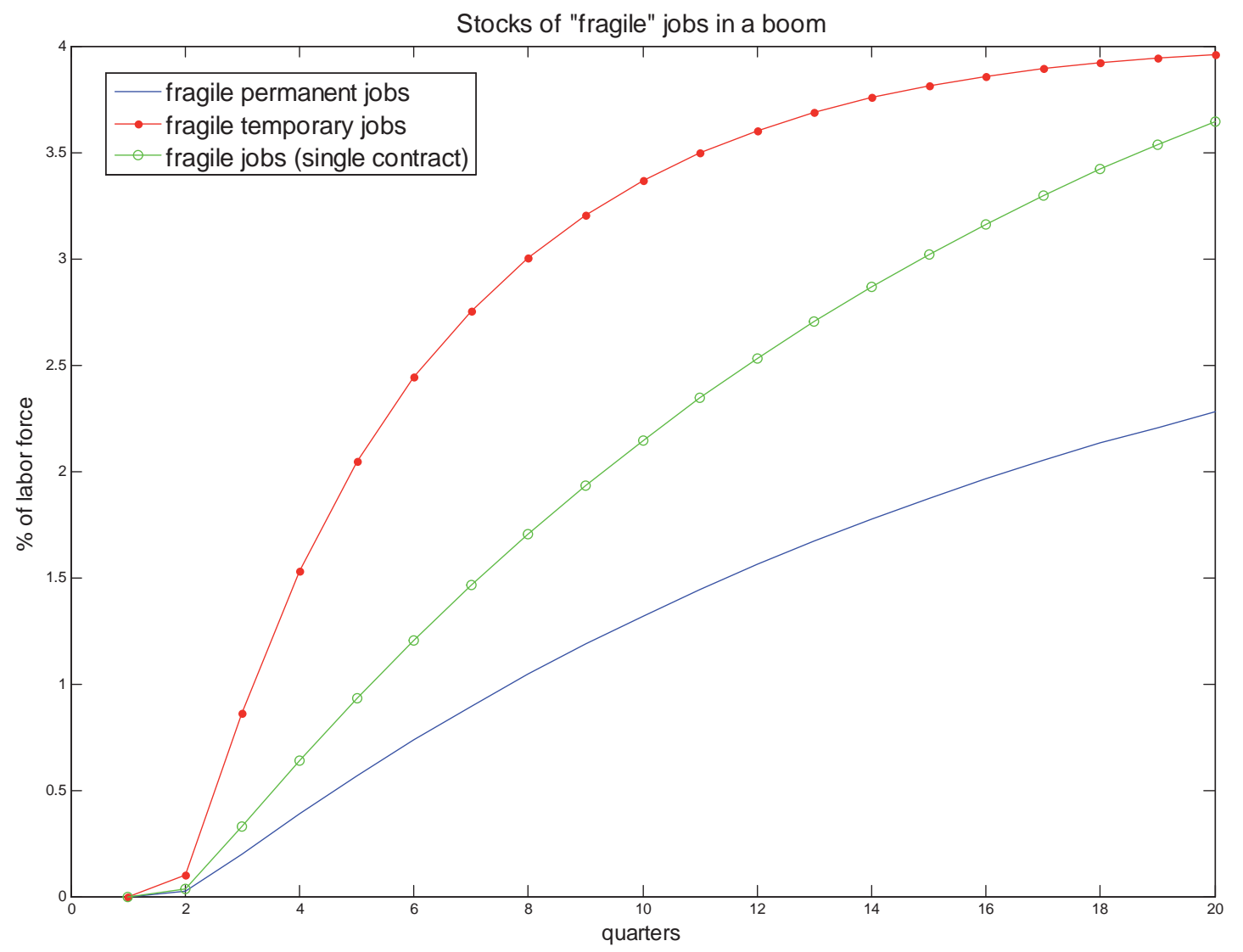

Figure 8: Accumulation of fragile jobs

the hiring threshold and as the firing threshold for temporary workers. Therefore, in booms, some temporary workers are hired directly into a situation of fragility - all those with $z \in\left[R_{2}^{T}, R_{1}^{T}\right)$. In addition, temporary matches may become fragile due to idiosyncratic shocks, as permanent matches do.

Figure 8 shows how quickly fragile jobs accumulate during expansions. The horizontal axis represents the time since the start of the boom; the red line shows the stock of temporary jobs in interval $\left[R_{2}^{T}, R_{1}^{T}\right.$ ), and the blue line shows the stock of permanent jobs in $\left[R_{2}^{P}, R_{1}^{P}\right)$. Thus, the vertical height of the curve shows the stock of jobs that would be fired if a recession were to begin, as a function of the duration of the preceding boom. For example, the diagram shows that if a recession begins 
after a boom lasting eight quarters, the stock of jobs destroyed is approximately $4 \%$ of the labor force, and three-quarters of this job destruction affects temporary jobs.

\subsection{Eliminating duality}

Next, we study what would happen if we replaced the dual contracting structure assumed in our benchmark model with a single type of contract. We maintain all the parameters of our benchmark specification, except for the policy parameters that drive duality. Thus, we now assume all jobs have exactly the same level of firing costs, which we call $F^{*}$.

As for the timing of decisions, we assume that a matched pair observe their idiosyncratic productivity $z$ as soon as they meet. At this time, they must decide whether or not to form an employment relationship; if they do not, they can continue searching for other partners without paying the firing cost $F^{*}$. However, as soon as they begin working, they are legally considered employer and employee, and separation thereafter entails the cost $F^{*}$. The firm's surplus is therefore defined relative to the outside option $-F^{*}$, and thus total surplus includes $F^{*}$ :

$$
S(z, y)=W(z, y)-U(y)+J(z, y)-V(y)+F^{*}
$$

where free entry, as before, implies $V(y)=0 .{ }^{14}$

Under these timing assumptions, there are two relevant reservation thresholds in any aggregate state $y$. There is a threshold $R^{N}(y)$ above which a pair will form a relationship upon meeting, which is determined by

$$
J\left(R^{N}(y), y\right)=0 \quad \rightarrow \quad S\left(R^{N}(y), y\right)=\frac{F^{*}}{1-\eta}>0
$$

There is also a threshold $R^{D}(y)$ for destruction of any existing match, which is simply determined by the absence of any joint surplus from continuation:

$$
S\left(R^{D}(y), y\right)=J\left(R^{D}(y), y\right)+F^{*}=W\left(R^{D}(y), y\right)-U(y)=0
$$

The surplus function $S(z, y)$ is monotonically increasing for the same reasons we saw in the baseline model, and therefore we conclude that $R^{D}(y)<R^{N}(y)$ in each aggregate state $y$.

Table 4 shows the effect of unifying the labor market under several possible levels of the firing cost $F^{*}$. First, we consider the case $F^{*}=F$, setting the firing cost in

\footnotetext{
${ }^{14}$ The value function notation in this section is the same as in our benchmark model except that, in the absence of duality, we can suppress the subscripts that indicate the two types of labor.
} 


\begin{tabular}{|c|c|c|c|c|c|}
\hline Variable & & \multicolumn{4}{|c|}{ Single contract } \\
\hline & Dual & Same F & Same & Same & Same \\
\hline & 2.0642 (perm) & wo pertiv & werage 1 & octed 1 & тареб \\
\hline Firing cost & 0 (temp) & 2.0642 & 1.3996 & 1.1170 & 0.3645 \\
\hline $\begin{array}{l}\text { Costs paid/GDP } \\
\text { Stocks }\end{array}$ & $0.82 \%$ & $0.91 \%$ & $0.90 \%$ & $0.81 \%$ & $0.34 \%$ \\
\hline$u_{s s}$ & $10.09 \%$ & $12.03 \%$ & $12.22 \%$ & $11.94 \%$ & $10.10 \%$ \\
\hline$s d(u)$ & $1.08 \%$ & $0.82 \%$ & $0.89 \%$ & $0.89 \%$ & $0.81 \%$ \\
\hline Flows & & & & & \\
\hline$J C_{s s}=J D_{s s}$ & $4.62 \%$ & $1.78 \%$ & $2.34 \%$ & $2.60 \%$ & $3.28 \%$ \\
\hline$s d(J C)$ & $0.23 \%$ & $0.09 \%$ & $0.11 \%$ & $0.12 \%$ & $0.14 \%$ \\
\hline$s d(J D)$ & $0.60 \%$ & $0.25 \%$ & $0.32 \%$ & $0.34 \%$ & $0.37 \%$ \\
\hline
\end{tabular}

Table 4: Effects of unifying labor market. Quarterly frequency, detrended HP-1600, quantities expressed as \% of labor force.

the unified labor market equal to the cost $F$ of firing a permanent job under duality. Unsurprisingly, the labor market becomes less volatile, with the standard deviation of unemployment falling from $1.08 \%$ of the labor force under the dual structure, to $0.82 \%$. Simultaneously, the unemployment rate rises by two percentage points to $12 \%$. However, this experiment does not really inform us about the effects of duality; we are comparing a dual market to a unified market that also has more firing costs overall.

To evaluate the effects of duality per se, we need to hold firing costs fixed. The simplest way to do this is to compare the dual market to a unified market with the same average level of firing costs. In other words, since almost one third (32.20\%, to be precise) of all employees in the dual market have zero firing costs, the average firing cost in the dual market is $(1-0.3220)^{*} 2.0642=1.3996$. Therefore, the next column of Table 4 considers $F^{*}=1.3996$. Again, unifying the labor market makes it less volatile; this policy change reduces the standard deviation of the unemployment rate from $1.08 \%$ to $0.89 \%$ of the labor force, which is a $21 \%$ decrease in variability. Alternatively, we could set $F^{*}$ so that the steady flow of firing costs paid (as a fraction of GDP) in the single contract model, which is $\lambda G\left(R^{D}\right) n F^{*} / n E z$, equals the same quantity in the dual model, which is $\lambda G\left(R^{P}\right) n^{P} F / n E z$. By a numerical search, we find that this results in $F^{*}=1.1170$. This results in a similar drop in the standard deviation of unemployment.

Thus, unifying the labor market while holding firing costs fixed on average implies 
a substantial drop in volatility. Unfortunately, eliminating duality by itself does not seem to improve the labor market outcome, because it also implies a large rise in the unemployment rate, to $12.22 \%$ when $F^{*}=1.3996$, and to $11.94 \%$ when $F^{*}=1.1170$. In fact, this is unsurprising. These two experiments have imposed the same average firing costs as in the dual market (in two slightly different ways). But by imposing these costs on all contracts, firms expect to pay them earlier, on average, than they would do in the dual economy. Therefore, effectively, we are making firing more expensive in discounted terms.

Therefore, another alternative is to choose the level of firing costs that lowers the steady state unemployment rate of the single contract model back down to the level associated with the steady state of the dual labor market. This requires a very substantial decrease in firing costs, to $F=0.3645$, lowering the steady state flow of firing costs paid by almost $60 \%$. This also implies a large decrease in the standard deviation of unemployment, from $1.08 \%$ to $0.81 \%$, representing a decrease in variability of $33 \%$. Figure 9 shows a simulated example of the fluctuations of the unified labor market (with $F=0.3645$ ). For comparability, it is simulated under exactly the same shock sequence as the dual example in Fig. 7 .

\subsection{Understanding the volatility of a unified labor market}

We have seen that imposing a single contract type substantially decreases labor market volatility over a wide range of possible firing costs in the unified contract. To understand this result, it helps to recall the fourth factor (D) mentioned in Section 5.1, where we compared the fluctuations of temporary and permanent employment. We observed that in the dual market, some temporary workers are hired directly into a situation of fragility, lying below the firing margin $R_{1}^{T}$, so that they expect to separate as soon as a recession arrives. Such immediate fragility does not occur in permanent contracts. New permanent contracts are always hired above the promotion threshold. Given our assumption that $F$ is relatively large, all possible values of the promotion threshold $R^{C}(y)$ are greater than all possible values of the permanent firing threshold $R^{P}\left(y^{\prime}\right)$ for all possible $y$ and $y^{\prime}$. Therefore newly formed permanent contracts never lie in the fragility interval $\left[R_{2}^{P}, R_{1}^{P}\right)$.

In all the examples of unified labor markets considered in Table 4, the firing cost $F^{*}$ is sufficiently large so that both the destruction thresholds are below both the creation thresholds:

$$
R_{2}^{D}<R_{1}^{D}<R_{2}^{N}<R_{1}^{N}
$$

Therefore, newly formed matches in the single-contract environment never lie in the fragility interval $\left[R_{2}^{D}, R_{1}^{D}\right)$. Instead, in the unified labor market, fragile jobs are 

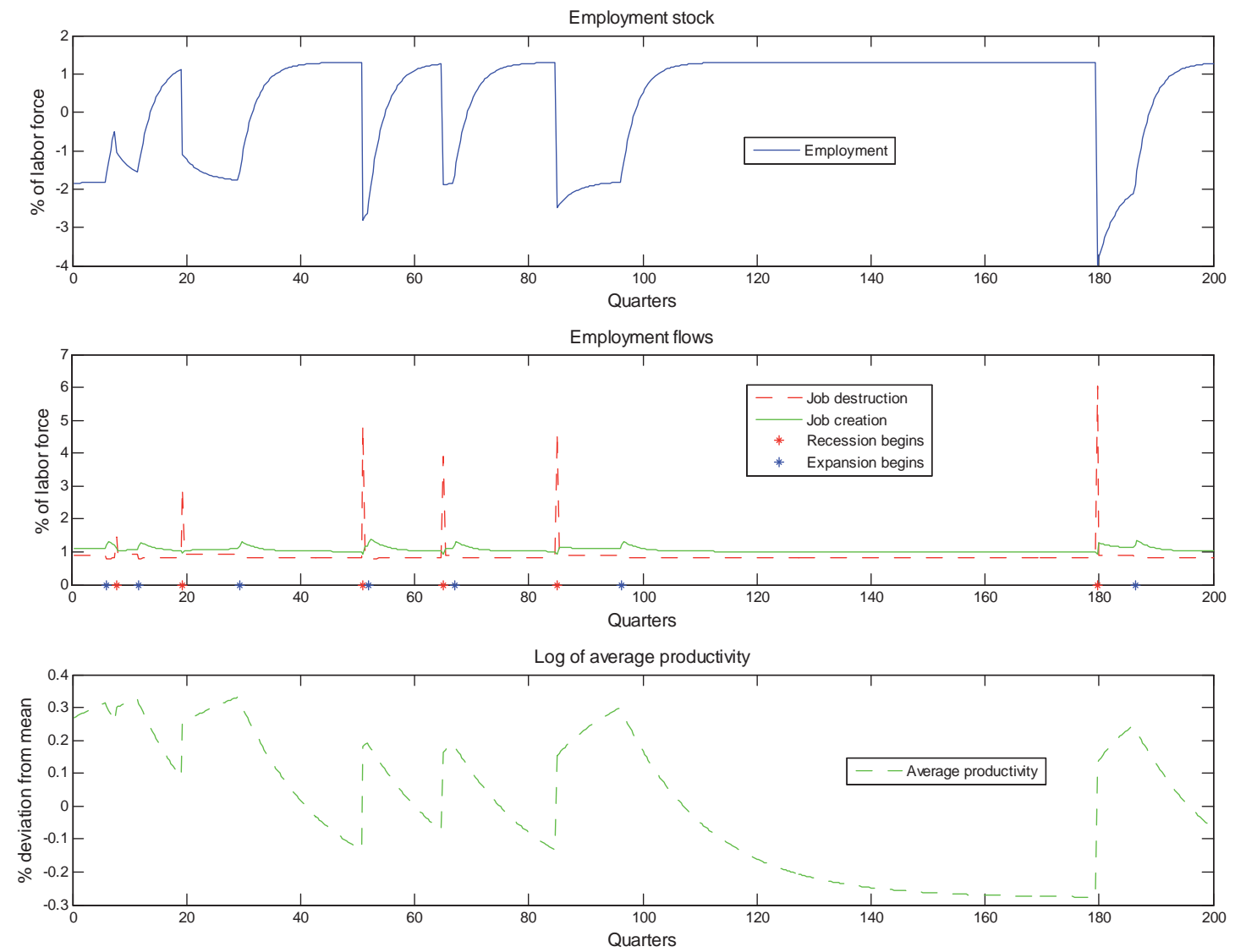

Figure 9: Dynamics: single contract, fixing employment

created only through negative idiosyncratic shocks - matches which were initially productive enough for hiring under the single contract (which makes them immediately subject to firing costs) can only become fragile if something about the specific situation of the worker or the firm changes sufficiently to push the match down towards the firing margin.

In other words, fragile jobs accumulate in the unified labor market by exactly the same mechanism as in the permanent component of the dual labor market. Given that the technological parameters governing the unified market are exactly the same as those in our dual market simulation, fragile job accumulation in the unified labor market is quantitatively similar to accumulation of fragile permanent jobs in the dual market, as can be seen from the green curve in Fig. 8. Therefore, there is 


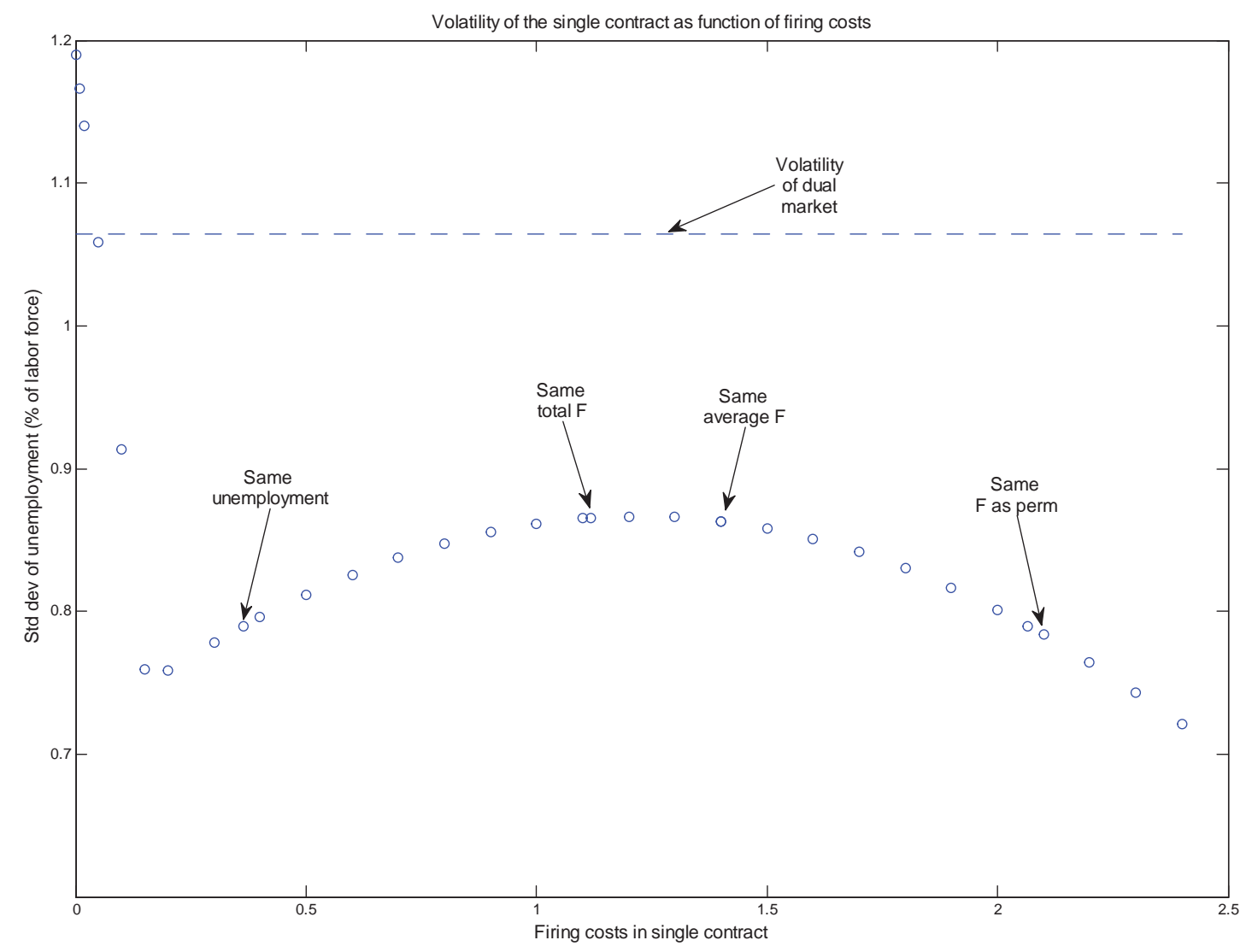

Figure 10: Single contract: unemployment volatility as function of firing cost, $b=$ $0.8 E z$

substantially less volatility of job destruction in the unified labor market than there is in the dual labor market, where destruction of temporary jobs is the most important source of cyclical employment fluctuations.

How general is this result? Figure 10 graphs the volatility of the unified labor market as a function of the firing costs associated with the single contract. We observe that the unified market is substantially less volatile than the dual benchmark model, except at the very lowest level of $F$. It is inevitable that this contrast in volatilities should disappear at some sufficiently low level of $F$, because when firing costs are exactly zero the dual and unified labor markets are equivalent. As we see in Figure 11, there is very little change in the volatility of the unified market until $F$ is almost zero, at which point the unified market's behavior suddenly changes. 
This rather dramatic change in the behavior of the single-contract market is caused by a change in in the order of the thresholds. For large $F$, we know that the highest destruction threshold, $R_{1}^{D}$, lies below the lowest creation threshold, $R_{2}^{N}$, so newly hired jobs are never fragile. But as $F$ approaches zero, the destruction thresholds converge towards the creation thresholds. Therefore, for sufficiently small but positive $F$, the order of the thresholds changes to

$$
R_{2}^{D}<R_{2}^{N}<R_{1}^{D}<R_{1}^{N}
$$

With this ordering, matches with productivity in the central interval $\left[R_{2}^{N}, R_{1}^{D}\right)$ are hired in booms but fired when recessions arrive. In other words, $\left[R_{2}^{N}, R_{1}^{D}\right)$ is an interval in which newly-created jobs are fragile. With this ordering of reservation thresholds, fragile jobs accumulate much more rapidly, just as they do for temporary jobs in the dual labor market.

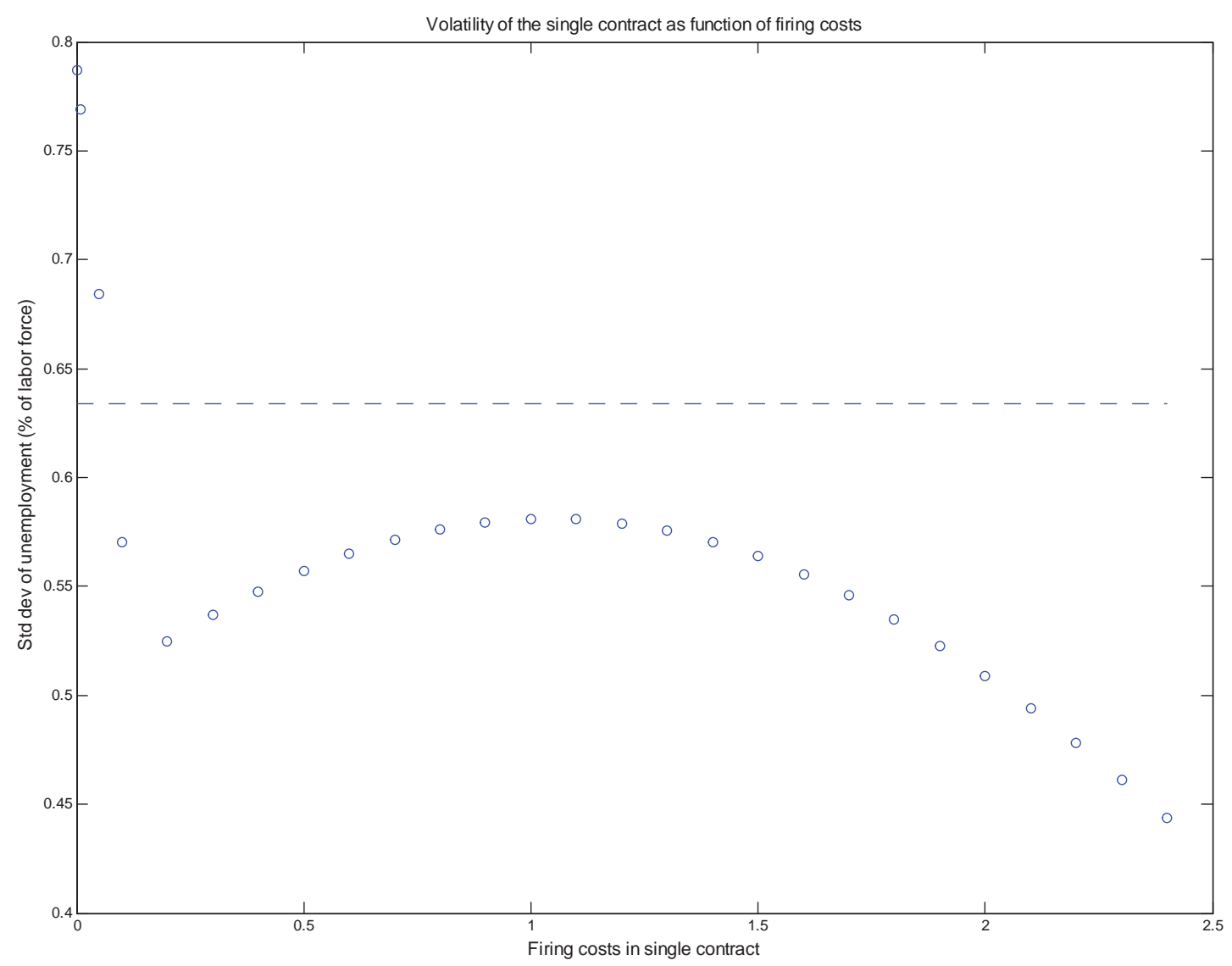

Figure 11: Single contract: unemployment volatility as function of firing cost, $b=$ $0.72 E z$ 
We further explore the effects of duality in Fig. 11, which is the same as Fig. 10, except that it is calculated at a 10\% lower level of unemployment benefits. Qualitatively, the results are similar to those in Fig. 10, but the overall level of volatility is much lower; under a dual labor market, the standard deviation of unemployment is $0.64 \%$ of the labor force when $b=0.72 E z$, as opposed to $1.08 \%$ when $b=0.8 E z$. As before, unifying the labor market lowers labor market volatility (from $0.64 \%$ to $0.58 \%$, roughly an $11 \%$ decrease), except at extremely low levels of the firing cost. Interestingly, the decrease in volatility caused by unifying the labor market is smaller, both in absolute and proportional terms, when $b$ is lower. In other words, the volatility caused by a dual labor market may be further exacerbated by a high unemployment benefit.

Summarizing, at an extremely low level of $F$, employment fluctuations in the unified labor market behave like those of the temporary component of the dual labor market. However, for a much wider range of values of $F$, employment fluctuations in the unified labor market behave like those of the permanent component of the dual labor market. The parameterization that best fits Spanish data clearly lies in the latter range, which means that the duality of Spain's labor market contributes to its remarkable volatility.

\section{Conclusions}

In this paper, we have studied the effect of labor market duality on labor market volatility in the context of the Mortensen-Pissarides (1994) model of job creation and destruction. Assuming autocorrelated match-specific productivity, our model implies that a mass of "fragile" jobs builds up in booms, which are subsequently destroyed when the economy enters a recession. These spikes of destruction of fragile jobs - especially fragile temporary jobs - account for much of the cyclical variation of unemployment. After calibrating our model to the Spanish labor market, we find that fragile temporary jobs build up faster in booms than fragile permanent jobs do, and therefore more temporary than permanent jobs are destroyed at the onset of recessions, even though on average the stock of temporary jobs is only half that of permanent jobs.

We then compare the labor market volatility under a dual contract regime to the volatility obtained when there is only a single contract type, so that all jobs have 
the same firing cost. In order to isolate the effects of duality per se, as opposed to the effect of changing the level of firing costs, we focus on a unified market with a firing cost equal to the average firing cost in the dual economy (meaning the average across all workers in the economy, including temps). Unifying the labor market in this way causes the standard deviation of unemployment to drop by $21 \%$. Moreover, the unified economy fluctuates similarly under many alternative levels of firing costs. We find that the market with a single contract type has a volatility between $21 \%$ and $33 \%$ lower than that of the dual market, depending on whether the firing cost in the single contract equals the firing cost of the permanent workers in the dual market, or the average firing cost in the dual market, or equalizes the total flow of firing costs as a fraction of GDP, or equalizes the unemployment rate of the unified economy to that in the dual benchmark.

The intuition behind this result is quite straightforward. With firing costs, newly formed jobs must have relatively high productivity (to compensate the firm for possible future firing payments), and therefore lie far above the firing margin. In jobs without firing costs, firms are instead willing to hire workers with productivity arbitrarily close to the firing margin. That is, in the absence of firing costs, some job matches are already in a "fragile" situation at the time of hiring, and are thus vulnerable to separation whenever the aggregate state of the economy declines. In the presence of firing costs, jobs do not become fragile until a match-specific shock causes a substantial change in productivity. This is why fragile temporary jobs accumulate much more rapidly in expansions in our dual market model than fragile permanent jobs do, resulting in a big spike of firing of temporary jobs when a recession hits. In a unified market (except in the case of near-zero firing costs), all jobs act like the permanent component of the dual market; newly-hired jobs are never fragile, so the stock of fragile jobs builds up slowly in booms and less firing occurs in recessions.

Most previous studies of matching models with a dual contract structure did not address the issue of volatility, because they looked only at steady states. The most closely related previous study (Sala, Silva, and Toledo 2009) did not point out that a dual market should have a greater volatility than a unified market with the same average firing costs. The reason their results differ from ours is that they assumed iid match productivity. Their assumption implies that any two jobs of the same contract type have exactly the same probability of separation in the next periodin other words, their model has no fragile jobs. By studying the more realistic but more difficult case of autocorrelated match productivity, we find that fragile jobs are the key to understanding cyclical volatility.

Our novel findings help explain the exceptional degree of employment volatility observed in the starkly dual Spanish labor contracting environment. Thus, elimi- 
nating duality while holding the average firing cost unchanged would decrease the volatility of the Spanish labor market. However, by itself this change would not necessarily be beneficial, because we calculate that it increases the long-run average unemployment rate by two percentage points. To eliminate duality without raising the level of unemployment, a substantial cut in the level of firing costs would also be required. We calculate that eliminating duality, accompanied by this reduction in firing costs, would also raise GDP net of firing costs by $5 \%$, compared to the effect of eliminating duality alone.

In addition to duality, our results also point to the overall level of social protectionproxied in our model by the income $b$ available to the unemployed - as a contributing factor to the volatility of the Spanish economy. In our simulations, increasing $b$ raises both the mean rate of unemployment and its volatility, though we should note that some of the effects we attribute to $b$ may actually represent the effects of wage rigidity, a factor omitted from our model. The effects of social protection are large: volatility falls more in response to a 4 percentage point decline in $b$ than it does in response to the elimination of labor market duality, and this stabilization is accompanied by a decrease in mean unemployment of 2.25 percentage points.

Obviously, this does not imply that lowering social protection would increase social welfare. A high level of $b$ means that workers suffer less from unemployment; this is part of the reason it leads to higher and more volatile unemployment in equilibrium. A welfare analysis which would weigh the benefits of this protection against its cost in terms of unemployment is beyond the scope of this paper. But the high level of social protection does help us understand the remarkable lack of political pressure for reform in the face of unemployment rates rarely experienced by other developed economies. Unfortunately, the increased expenditure and decreased employment, productivity, and taxes implied by this protection represent a substantial threat to the public finances in the not-too-distant future. 


\section{References}

BABECKÝ, J., C. VAN DER CRUIJSEN-KNOBEN and S. FAHR (2009). European labour markets in the current recession, mimeo, Czech National Bank.

BELOT, M., J. BOONE and J. VAN OURS (2002). Welfare effects of employment protection, CentER, Tilburg University, Discussion Paper No. 2002-48.

BENTOLILA, S., and G. BERTOLA (1990). "Firing costs and labor demand: How bad is Eurosclerosis?", Review of Economic Studies, 54, pp. 381-402.

BENTOLILA, S., P. CAHUC, J. J. DOLADO and T. LE BARBANCHON (2009): Two-tier labor markets in a deep recession: France vs. Spain, mimeo.

BENTOLILA, S., and A. ICHINO (2008). "Unemployment and consumption near and far away from the Mediterranean", Journal of Population Economics, 21, pp. 255-280.

BENTOLILA, S., and G. ST. PAUL (1992). "The macroeconomic impact of flexible labor contracts, with an application to Spain", European Economic Review, 36, pp. 1013-1053.

BERTOLA, G., F. D. BLAU and L. M. KAHN (2003). Labor Market Institutions and Demographic Employment Patterns, mimeo.

BLANCHARD, O., and A. LANDIER (2002). "The Perverse Effects of Partial Labour Market Reforms: Fixed Duration Contracts in France", The Economic Journal, 112, pp. F214-F244.

BLANCHARD, O., and J. WOLFERS (2000). "The Role of Shocks and Institutions in the Rise of European Unemployment", The Economic Journal, 110, pp. C1-C33.

BOERI, T., and P. GARIBALDI (2007). "Two-tier reforms of employment protection: a honeymoon effect?", The Economic Journal, 117, pp. F357-F385.

BOERI, T., and J. F. JIMENO (2005). "The Effects of Employment Protection Legislation: Learning from Variable Enforcement", European Economic Review, 49, pp. 2057-2077.

BOOTH, A. L., J. J. DOLADO and J. FRANK (2002). "Introduction: Symposium on Temporary Work", The Economic Journal, 112, pp. F181-F188.

BURDA, M. (1992). "A Note on Firing Costs and Severance Benefits in Equilibrium Unemployment", Scandinavian Journal of Economics, 94, pp. 479-489.

CABAlLERO, R., E. ENGEL and A. MICCO (2003). Job Security and Speed of Adjustment, mimeo.

CAHUC, P., and F. POSTEL-VINAY (2002). "Temporary jobs, Employment Protection, and Labor Market Performance", Labour Economics, 9, pp. 63-91.

CARDULlO, G., and B. VAN DER LINDEN (2006). Employment Changes and 
Substitutable Skills: An Equilibrium Matching Approach, IZA Discussion Paper No. 2073.

COSTAIN, J., and M. JANSEN (2009). Employment fluctuations under downward wage rigidity: the role of moral hazard, IZA Discussion Paper No. 4344.

COSTAIN, J., and M. REITER (2008). "Business cycles, unemployment insurance, and the calibration of matching models", Journal of Economic Dynamics and Control, 32 (4), pp. 1120-1155.

DOLADO, J. J., C. GARCÍA-SERRANO and J. F. JIMENO (2002). "Drawing Lessons from the Boom of Temporary Jobs in Spain", The Economic Journal, 2002, pp. F270-F295.

DOLADO, J. J., M. JANSEN and J. F. JIMENO (2005). Dual Employment Protection Legislation: A Framework for Analysis, CEPR, Discussion Papers No. 5033.

- (2007). "A Positive Analysis of Targeted Employment Protection", Berkeley Electronic Press: Journal of Macroeoconomics: Topics, vol. 7, Issue 1.

- (2009). "On-the-Job Search in a Matching Model with Heterogeneous Jobs and Workers", Economic Journal, Vol. 119, 534, pp. 200-228.

GARIBALDI, P., and G. VIOLANTE (2005). "The Employment Effects of Severance Payments with Wage Rigidity", The Economic Journal, 115, pp. 799-832.

HOPENHAYN, H. (2001). Labor Market Policies and Employment Duration: The Effects of Labor Market Reform in Argentina, mimeo.

IDB (2003). Good Jobs Wanted. Labor Markets in Latin America, Washington.

JIMENO, J. F., and D. RODRÍGUEZ-PALENZUELA (2002). Youth Unemployment in the OECD: Demographic Shifts, Labour Market Institutions, and Macroeconomic Shocks, FEDEA, Working Paper No. 2002-15.

KUGLER, A., J. F. JIMENO and V. HERNÁNZ (2003). Employment Consequences of Restrictive Employment Policies: Evidence from Spanish Labour Market Reforms, FEDEA, Working Paper No. 2003-14.

LAZEAR, E., (1990). "Job security provisions and employment", Quarterly Journal of Economics, 105, pp. 699-726.

LJUNGQVIST, L. (2002). "How do lay-off costs affect employment?", The Economic Journal, 112, October, pp. 829-853.

MORTENSEN, D. T., and C. A. PISSARIDES (1994). "Job creation and job destruction in the theory of unemployment", Review of Economic Studies, 61, pp. 397-415.

- (1999). "New Developments in Models of Search in the Labor Market", in O.C. Ashenfelter and D. Card (eds.), Handbook of Labor Economics, Amsterdam: North-Holland, pp. 2567-2628. 
- (2003). "Taxes, subsidies, and equilibrium labour market outcomes", in Designing Inclusion: Tools to Raise low-end Pay and Employment in Private Enterprise, edited by Edmund S. Phelps, Cambridge: Cambridge University Press.

NEUMARK, D., and W. WASCHER (2003). Minimum Wages, Labor Market Institutions, and Youth Employment: A Cross-National Analysis, mimeo.

NICKELL, S., and R. LAYARD (1999). "Labour market institutions and economic performance", in O. Ashenfelter and D. Card (eds.), Handbook of Labor Economics, Amsterdam: North Holland.

NUNZIATA, L., and S. STAFFOLANI (2001). The employment effects of shortterm contracts regulations in Europe, mimeo.

OECD (2009). Addressing the labour market challenges of the economic downturn: A Summary of country responses to the OECD-EC questionnaire, mimeo.

PETRONGOLO, B., and C. PISSARIDES (2001). "Looking into the black box: A survey of the matching function", Journal of Economic Literature, 39, pp. 390-431.

SAINT-PAUL, G. (1996). "Exploring the political economy of labour market institutions", Economic Policy, 23, pp. 265-300.

- (2000). The Political Economy of Labor Market Reforms, Oxford: Oxford University Press.

SALA, H., and J. I. SILVA (2009). "Flexibility at the margin and labour market volatility: The case of Spain", Investigaciones Económicas, Vol. XXXIII (2), pp. $145-178$.

SALA, H., J. I. SILVA and M. TOLEDO (2009). Flexibility at the margin and labour market volatility in OECD countries, mimeo.

WASMER, E. (1999). "Competition for Jobs in a Growing Economy and the Emergence of Dualism in Employment", The Economic Journal, 109, pp. 349-375. 


\section{Appendix: Analyzing the surplus functions}

Here we generalize the analysis of the surplus functions from Section 4 to allow for $N$ possible aggregate states $y_{i}$. Following Costain and Jansen (2009), we describe a numerical method to calculate the slope on each interval and the jumps between intervals when the number and ordering of intervals is arbitrary.

\subsection{Partitioning the productivity space}

The Bellman equations (17)-(18) that define the surplus functions are continuous and differentiable at most but not all points. There are sudden changes in the form of equation (17) at points $z=R_{i}^{C}$ and $z=R_{i}^{T}$, and in equation (18) at the points $R_{i}^{P}$, for $i \in\{1,2, \ldots, N\}$. Therefore, as in Prop. 8 , it is convenient to analyze the surplus equations separately on each interval defined by two consecutive reservation thresholds. There are $N$ thresholds of each type, so the whole support of the productivity distribution can be broken into $3 N+1$ relevant intervals bounded by reservation thresholds or by the lowest and highest possible values of $z$. Numbering backwards, we can list all the thresholds as

$$
r_{3 N} \leq r_{3 N-1} \leq r_{3 N-2} \leq \ldots \leq r_{2} \leq r_{1}
$$

where for each $j \in\{1,2, \ldots, 3 N\}, r_{j}=R_{k}^{a}$, with $a \in\{T, C, P\}$ and $k \in\{1,2, \ldots, N\}$. Then the typical interval takes the form

$$
I_{j}=\left[r_{j}, r_{j-1}\right)
$$

where $r_{j}$ and $r_{j-1}$ are both reservation productivities.

If we then define $r_{3 N+1}=0$ and $r_{0}=\infty$, then the full set of relevant intervals is

$$
\begin{aligned}
I_{3 N+1}= & {\left[r_{3 N+1}, r_{3 N}\right)=\left[0, R_{N}^{P}\right) } \\
& \ldots \\
I_{j}= & {\left[r_{j}, r_{j-1}\right) } \\
& \ldots \\
I= & {\left[r_{1}, r_{0}\right]=\left[R_{1}^{C}, \infty\right) }
\end{aligned}
$$

Note that we have not ruled out the possibility that two or more reservation productivities might coincide, $r_{j}=r_{j-1}$; in this case interval $I_{j}$, by definition, is empty.

Without loss of generality, we define surplus to zero in the intervals where jobs separate. That is, $S^{T}(z, y)=0$ for $z<R^{T}(y)$, and $S^{P}(z, y)=0$ for $z<R^{P}(y)$. We now investigate what we can learn from the Bellman equations (17) and (18) in the intervals where jobs continue. 


\subsection{Surplus slopes}

On each of the intervals $I_{j}=\left[r_{j}, r_{j-1}\right)$, the surplus functions are continuously differentiable. Differentiating both sides of (18), we obtain

$$
(r+\rho+\lambda+\mu) \frac{\partial S^{P}}{\partial z}(z, y)=1+\mu \sum_{y^{\prime}: R^{P}\left(y^{\prime}\right) \leq z} M_{y^{\prime} \mid y} \frac{\partial S^{P}}{\partial z}\left(z, y^{\prime}\right)
$$

Notice that this equation does not depend on $z$ except insofar as it varies from one interval to another. Therefore, for concise notation, we write the slope of the surplus function for permanent jobs in state $y_{i}$ in interval $I_{j}$ as $\sigma_{i j}^{P} \equiv \frac{\partial}{\partial z} S^{P}\left(z, y_{i}\right), z \in I_{j}$, so (33) can be rewritten as

$$
\sigma_{i j}^{P}=(r+\rho+\lambda+\mu)^{-1}\left[1+\mu \sum_{k: R_{k}^{P} \leq r_{j}} M_{y_{k} \mid y_{i}} \sigma_{i k}^{P}\right]
$$

The terms that appear on the right-hand side of this equation involve all the slopes $\frac{\partial S^{P}}{\partial z}\left(z, y_{k}\right)$ associated with states $y_{k}$ which continue in interval $I_{j}$ - that is, all the $k$ satisfying $R^{P}\left(y_{k}\right) \leq r_{j}$. But these are exactly the same slopes that are determined by (34) - we use (34) to calculate $\sigma_{i j}^{P}$ for each $i$ satisfying $R^{P}\left(y_{i}\right) \leq r_{j}$. Therefore (34) gives us the right number of equations and unknowns to determine all the nonzero slopes $\sigma_{i j}^{P}$ associated with interval $I_{j}$.

Similarly, differentiating both sides of (17), we obtain

$$
(r+\rho+\lambda+\delta+\mu) \frac{\partial S^{T}}{\partial z}(z, y)=1+\delta \mathbf{1}\left(z \geq R^{C}(y)\right) \frac{\partial S^{P}}{\partial z}(z, y)+\mu \sum_{y^{\prime}: R^{T}\left(y^{\prime}\right) \leq z} M_{y^{\prime} \mid y} \frac{\partial S^{T}}{\partial z}\left(z, y^{\prime}\right)
$$

Defining $\sigma_{i j}^{T} \equiv \frac{\partial}{\partial z} S^{T}\left(z, y_{i}\right), z \in I_{j}$, we can rewrite this as

$$
\sigma_{i j}^{T}=(r+\rho+\lambda+\delta+\mu)^{-1}\left[1+\delta \mathbf{1}\left(r_{j} \geq R_{i}^{C}\right) \sigma_{i j}^{P}+\mu \sum_{k: R_{k}^{T} \leq r_{j}} M_{y_{k} \mid y_{i}} \sigma_{k j}^{T}\right]
$$

Equation (36), gives us the right number of equations and unknowns to determine all the nonzero slopes $\sigma_{i j}^{T}$ associated with interval $I_{j}$, just as (34) did for the slopes $\sigma_{i j}^{P}$. In fact, these equation systems tightly bound the slopes of the surplus functions: 
Lemma 9 For $z>R^{P}(y)$, the surplus function for permanent contracts $S^{P}(z, y)$ is strictly increasing in $z$. At any $z$ that is not a permanent firing threshold $\left(z \neq R^{P}\left(y_{j}\right)\right.$ for $j \in\{1,2, \ldots, N\})$, the $z$-derivative of $S^{P}(z, y)$ is well-defined, satisfying

$$
\frac{1}{r+\rho+\lambda+\mu} \leq \frac{\partial}{\partial z} S^{P}(z, y) \leq \frac{1}{r+\rho+\lambda} .
$$

For $z>R^{T}(y)$, the surplus function for temporary contracts $S^{T}(z, y)$ is strictly increasing in $z$. At any $z$ that is not a reservation threshold $\left(z \neq R^{i}\left(y_{j}\right)\right.$ for $i \in$ $\{T, C, P\}$ and $j \in\{1,2, \ldots, N\})$, the $z$-derivative of $S^{T}(z, y)$ is well-defined, satisfying

$$
\frac{1}{r+\rho+\delta+\lambda+\mu} \leq \frac{\partial}{\partial z} S^{T}(z, y) \leq \frac{1}{r+\rho+\delta+\lambda}\left(1+\frac{\delta}{r+\rho+\lambda}\right) .
$$

Proof. Systems (34) is a linear equation system, involving equal numbers of equations and unknowns. More precisely, it can be viewed as a fixed point problem involving one equation for each of the slopes $\sigma_{i j}^{P}$ associated with states $y_{i}$ satisfying $R^{P}\left(y_{i}\right) \leq r_{j}$. Note that the Markov property of matrix $M$ implies that $\sum_{k: R^{P}\left(y_{k}\right) \leq r_{j}} M_{y_{k} \mid y_{i}} \leq 1$. Given this fact, it is easy to verify that the mapping defined by (33) satisfies Blackwell's monotonicity and discounting conditions, with discount factor $\frac{\mu}{r+\rho+\lambda+\mu}$. Therefore the mapping is a contraction, and has a unique fixed point.

Let $\bar{c}_{j}$ be a vector of ones with length equal to the number of states $y_{i}$ satisfying $R^{P}\left(y_{i}\right) \leq r_{j}$. If we apply mapping (33) to the vector $\bar{v}_{j} \equiv(r+\rho+\lambda)^{-1} \bar{c}_{j}$, the resulting vector is less than or equal to $\bar{v}_{j}$. Likewise, if we apply (33) to $\underline{v}_{j} \equiv(r+\rho+\lambda+\mu)^{-1} \bar{c}_{j}$, the resulting vector is greater than or equal to $\underline{v}_{j}$. Therefore the fixed point of (33) lies between $\bar{v}_{j}$ and $\underline{v}_{j}$. We therefore conclude that for any $z>R^{P}(y)$ which is not a reservation threshold, the slope of $S^{P}$ is exists and satisfies (37).

The same argument can be used to bound the slopes $\sigma_{i j}^{T}$ determined by (36), taking as given the slopes $\sigma_{i j}^{P}$.

QED.

\subsection{Surplus jumps}

While the surplus functions are continuously differentiable inside the intervals $I_{j}$, new terms come into play on the right-hand sides of (17) and (18) as we pass from one interval to the next, which means the surplus functions may be discountinuous at the reservation productivities. To be precise, if we define

$$
\Delta(z, y) \equiv \lim _{d z \rightarrow 0}\left[S^{T}(z+d z, y)-S^{T}(z-d z, y)\right],
$$


then $\Delta(z, y)$ is zero at all points that are not reservation thresholds.

The Bellman equation for the surplus of permanent jobs, (18), shows new terms that enter at the thresholds $R^{P}(y)$. However, because of the equilibrium condition $S^{P}\left(R^{P}(y), y\right)=0$ (and the fact that we define $S^{P}(z, y)=0$ for $z<R^{P}(y)$ ), these new terms do not generate discontinuities at $R^{P}(y)$. Therefore, the surplus of permanent jobs, $S^{P}$, is a continuous function of $z$.

Likewise, the Bellman equation for the surplus of temporary jobs, (17), looks like it might be discontinuous at the thresholds $R^{T}(y)$, but actually there is no discontinuity at these points because of the equilibrium condition $S^{T}\left(R^{T}(y), y\right)=0$.

On the other hand, discontinuities do arise in $S^{T}$ at the points $z=R^{C}\left(y^{\prime}\right)$ for $y^{\prime} \geq y$. To show this, we can use Bellman equation (17) to calculate the jump at any $z$. Since $S^{P}(z, y)$ is itself a continuous function, we have

$$
\begin{gathered}
(r+\rho+\lambda+\delta+\mu) \Delta(z, y)-\mu \sum_{y^{\prime}: R^{T}\left(y^{\prime}\right) \leq z} M_{y^{\prime} \mid y} \Delta\left(z, y^{\prime}\right)= \\
=\delta \lim _{d z \rightarrow 0}\left\{\mathbf{1}\left(z+d z \geq R^{C}(y)\right)\left(S^{P}(z+d z, y)-F\right)-\mathbf{1}\left(z-d z \geq R^{C}(y)\right)\left(S^{P}(z-d z, y)-F\right)\right\} \\
=\delta \lim _{d z \rightarrow 0}\left\{\mathbf{1}\left(z+d z \geq R^{C}(y)\right)-\mathbf{1}\left(z-d z \geq R^{C}(y)\right)\right\}\left(S^{P}(z, y)-F\right) \\
=\delta\left\{\mathbf{1}\left(z=R^{C}(y)\right)\right\}\left(S^{P}(z, y)-F\right)=\delta\left\{\mathbf{1}\left(z=R^{C}(y)\right)\right\} \frac{\eta}{1-\eta} F
\end{gathered}
$$

To calculate all the jumps at point $R_{i}^{C}$, we can therefore calculate

$$
\Delta\left(R_{i}^{C}, y_{j}\right)=(r+\rho+\lambda+\delta+\mu)^{-1}\left[\frac{\delta \eta}{1-\eta} F+\mu \sum_{y_{k}: R_{k}^{T} \leq R_{i}^{C}} M_{y_{k} \mid y_{j}} \Delta\left(R_{i}^{C}, y_{k}\right)\right]
$$

which is a system of equations only involving the jumps at $z=R_{i}^{C}$. It is a system of equations involving the unknown jumps $\Delta\left(R_{i}^{C}, y_{k}\right)$ in the surplus functions of all states $k$ such that $R_{k}^{T} \leq R_{i}^{C}$. There is one equation for each of these unknowns, so there is a unique solution.

Moreover, like the equations (34) and (36) that determined the slopes, (39) can be regarded as a fixed point operator which satisfies the contraction property. Therefore we can bound the jumps as follows.

Lemma 10 For each $y$, the surplus function for permanent contracts $S^{P}(z, y)$ is a continuous function, which equals 0 at $z \leq R^{P}(y)$. For each $y$, the surplus function for temporary contracts $S^{T}(z, y)$ equals 0 at $z \leq R^{T}(y)$. For $z>R^{T}(y)$ it is strictly 
increasing in $z$. Furthermore, at any $z$ that is not a promotion threshold $\left(z \neq R^{C}\left(y_{j}\right)\right.$ for $j \in\{1,2, \ldots, N\}), S^{T}(z, y)$ is a continuous function. At the promotion thresholds, it jumps up by a nonnegative amount $\Delta\left(R^{C}\left(y_{j}\right), y_{i}\right)$, given by (39), bounded by

$$
\frac{1}{r+\rho+\delta+\lambda+\mu}\left(\frac{\delta \eta F}{1-\eta}\right) \leq \Delta\left(R^{C}\left(y_{j}\right), y_{i}\right) \leq \frac{1}{r+\rho+\delta+\lambda}\left(\frac{\delta \eta F}{1-\eta}\right) .
$$

We omit the proof of Lemma 10, because it is essentially the same as that of Lemma 9.

\subsection{Monotonicity with respect to $y$}

Lemma 11 Holding fixed the aggregate equilibrium $\theta(y)$, for a given worker-firm pair there exist surplus functions $S^{T}$ and $S^{P}$, and reservation thresholds $R^{T}, R^{C}$, and $R^{P}$, that are Pareto optimal from the point of view of the pair. Moreover, if productivity satisfies Assumption 1 and the aggregate equilibrium satisfies Assumption 5, then $S^{T}(z, y)$ and $S^{P}(z, y)$ are both increasing in $y$.

Proof. This is just a restatement of Prop. 1 and Corollary 2 in Costain and Jansen (2009).

They analyze the partial equilibrium decision of a matched pair - that is, the choice of wages and reservation thresholds from the point of view of the pair, holding fixed tightness as a function of $y$ in the rest of the economy. They write the pair's surplus as a fixed point that takes as given the reservation thresholds, and the reservation thresholds as a fixed point that takes as given the surplus. Following Rustichini (1998), they use the monotonicity properties of the fixed point operators to show that there exists an unambiguously lowest fixed point of the reservation thresholds, corresponding to an unambiguously highest fixed point of the surplus functions. The same method used in their paper is applicable here. In other words, taking as given the behavior of the rest of the economy, there exists a reservation strategy that causes the pair to continue in the largest possible set of states $(x, y)$, and thereby maximizes the surplus of the pair in all states $(x, y)$, and is therefore preferred by both the worker and the firm.

Furthermore, assuming a first-order stochastic dominance property for $y$ as in Assumption 1, they show that if tightness satisfies Assumption 5, then surplus is increasing in $y$.

QED.

Lemma 12 Let $N=2$. Then Assumption 5 is satisfied if $d y \equiv y_{2}-y_{1}$ is sufficiently small. 
Proof. Here we assume $d y \equiv y_{2}-y_{1}$ is small enough so that we can characterize the how equilibrium changes when $y$ changes by means of a linear approximation in $d y$. We define the following notation: $d \theta=\theta_{2}-\theta_{1}=\theta\left(y_{2}\right)-\theta\left(y_{1}\right), d R^{T}=R_{2}^{T}-R_{1}^{T}$, $d R^{C}=R_{2}^{C}-R_{1}^{C}, d R^{P}=R_{2}^{P}-R_{1}^{P}, d S^{T}(z)=S^{T}\left(z, y_{2}\right)-S^{T}\left(z, y_{1}\right), d S^{P}(z)=$ $S^{P}\left(z, y_{2}\right)-S^{P}\left(z, y_{1}\right)$. We will perform linear approximations around the mean value of $y$, which we call $E y$.

We are assuming a non-negligible firing cost $F$, but arbitrarily small variation $d y$. We have proved earlier that for each $i, R_{i}^{P} \leq R_{i}^{T} \leq R_{i}^{C}$. The differences $d R^{T}$, $d R^{T}$, and $d R^{T}$ must be of order $d y$, which is arbitrarily small, so we conclude that both $R_{1}^{P}$ and $R_{2}^{P}$ are less than $R_{1}^{T}$ and $R_{2}^{T}$, which are both less than $R_{1}^{C}$ and $R_{2}^{C}$. However, we do not yet know the order of each pair of reservation productivities, so sometimes we will use the notation $R_{\max }^{T}=\max \left\{R_{2}^{T}, R_{1}^{T}\right\}, R_{\min }^{T}=\min \left\{R_{2}^{T}, R_{1}^{T}\right\}$, and analogous notation for $R^{C}$ and $R^{P}$.

It is easy to prove ${ }^{15}$ that $S^{P}\left(z, y_{2}\right)$ and $S^{P}\left(z, y_{1}\right)$ are parallel above $R_{\max }^{P}$, with slope $(r+\rho+\lambda)^{-1}$. Likewise, $S^{T}\left(z, y_{2}\right)$ and $S^{T}\left(z, y_{1}\right)$ are parallel in the interval $\left(R_{\max }^{T}, R_{\min }^{C}\right)$, with slope $(r+\rho+\lambda+\delta)^{-1}$, and they are again parallel above $R_{\max }^{C}$, with slope $(r+\rho+\lambda)^{-1}$.

The zero-profit condition implies the following identity:

$$
\frac{\eta c \theta(y)}{1-\eta}=\eta p(\theta(y)) \int_{R^{T}(y)}^{\infty} S^{T}(z, y) d G(z)=\eta p(\theta(y)) \int_{R_{\max }^{T}}^{\infty} S^{T}(z, y) d G(z)+O\left(d y^{2}\right)
$$

Note that the integral $\int_{R_{\min }^{T}}^{R_{\max }^{T}} S^{T}(z, y) d G(z)$ represents the area of a triangle with base and height both of order $O(d y)$, so the integral itself is of order $O\left(d y^{2}\right)$ and can be ignored. Linearizing and simplifying, we obtain

$$
\frac{\eta c}{1-\eta} d \theta=\frac{\eta p}{\epsilon} \int_{R^{T}} d S^{T}(z) d G(z)+O\left(d y^{2}\right)
$$

Here $p$ represents $p(\theta(y))$ evaluated at $E y$, and $\epsilon$ is the elasticity of the matching function with respect to unemployment. For concise notation, we have suppressed the upper index of integration, and we have written the lower index without specifying exactly which $R^{T}$ is meant, because up to a linear approximation integrating from $R_{\min }^{T}$ or $R_{\max }^{T}$ or $R^{T}(\theta(E y))$ is equivalent.

\footnotetext{
${ }^{15}$ Differentiate the Bellman equation for $S^{P}$, then guess that the slopes of $S^{P}\left(z, y_{2}\right)$ and $S^{P}\left(z, y_{1}\right)$ are equal. The guess is immediately verified, and we can solve for the slope.
} 
Above $R_{\max }^{P}, S^{P}\left(z, y_{2}\right)$ and $S^{P}\left(z, y_{1}\right)$ are parallel, so their difference is a constant which we will simply call $d S^{P}$. To calculate $d S^{P}$, we evaluate the Bellman equation (18) at $\left(R_{2}^{P}, y_{2}\right)$ and at $\left(R_{1}^{P}, y_{1}\right)$, where $S^{P}$ is zero:

$$
\begin{aligned}
& 0=R_{2}^{P}+y_{2}-b+(r+\rho) F-\frac{\eta c \theta_{2}}{1-\eta}+\lambda \int_{R_{2}^{P}} S^{P}\left(z, y_{2}\right) d G(z)+\mu_{1 \mid 2} \mathbf{1}\left(R_{2}^{P} \geq R_{1}^{P}\right) S^{P}\left(R_{2}^{P}, y_{1}\right)+O\left(d y^{2}\right) \\
& 0=R_{1}^{P}+y_{1}-b+(r+\rho) F-\frac{\eta c \theta_{1}}{1-\eta}+\lambda \int_{R_{1}^{P}} S^{P}\left(z, y_{1}\right) d G(z)+\mu_{2 \mid 1} \mathbf{1}\left(R_{1}^{P} \geq R_{2}^{P}\right) S^{P}\left(R_{1}^{P}, y_{2}\right)+O\left(d y^{2}\right)
\end{aligned}
$$

Subtracting these two equations, and moving $d R$ to the left-hand side of the equation, we obtain

$$
-d R=d y-\frac{\eta c}{1-\eta} d \theta+\lambda\left(1-G\left(R^{P}\right)\right) d S^{P}+\mu_{1 \mid 2} \mathbf{1}(d R \geq 0) S^{P}\left(R_{2}^{P}, y_{1}\right)-\mu_{2 \mid 1} \mathbf{1}(d R \leq 0) S^{P}\left(R_{1}^{P}, y_{2}\right)+O\left(d y^{2}\right)
$$

Now, consider the surplus equation 18 on the interval $\left(R_{\min }^{P}, R_{\max }^{P}\right)$. If $R_{1}^{P}>R_{2}^{P}$, that is, $d R<0$, which is the case we intuitively expect, then $S^{P}\left(z, y_{2}\right)$ is increasing from zero on $\left(R_{\min }^{P}, R_{\max }^{P}\right)$, with slope $\left(r+\rho+\lambda+\mu_{1 \mid 2}\right)^{-1}$. The geometry of this case requires $d S^{P}=-\left(r+\rho+\lambda+\mu_{1 \mid 2}\right)^{-1} d R>0$. If we instead consider the counterintuitive case $d R>0$, then $S^{P}\left(z, y_{1}\right)$ is increasing from zero on $\left(R_{\min }^{P}, R_{\max }^{P}\right)$, with slope $\left(r+\rho+\lambda+\mu_{2 \mid 1}\right)^{-1}$. In this case, $d S^{P}=-\left(r+\rho+\lambda+\mu_{2 \mid 1}\right)^{-1} d R<0$. In both cases, if we eliminate $d R$ from (42) and simplify, we obtain

$$
\left(r+\rho+\lambda G\left(R^{P}\right)+\mu\right) d S^{P}=d y-\frac{\eta c}{1-\eta} d \theta+O\left(d y^{2}\right)
$$

In order to complete our calculations, we will need to integrate $\int_{R^{T}} d S^{T}(z) d G(z)$, which requires us to know how $d S^{T}$ varies with $z$. More precisely, since we know some intervals where the $S^{T}$ functions are parallel, we can break the integral into smaller pieces as follows:

$$
\begin{gathered}
\left(G\left(R_{\min }^{C}\right)-G\left(R_{\max }^{T}\right)\right) d S^{T}\left(R_{\max }^{T}\right)+\left(G\left(R_{\max }^{C}\right)-G\left(R_{\min }^{C}\right)\right)\left[d S^{T}\left(R_{\min }^{C}\right)+O(d y)\right] \\
+\left(1-G\left(R_{\max }^{C}\right)\right) d S^{T}\left(R_{\max }^{C}\right)+O\left(d y^{2}\right)
\end{gathered}
$$

We can evaluate $d S^{T}$ at the most important points by following the same method we used to derive (43). First, consider $d S^{T}\left(R_{\max }^{T}\right)$, which is the distance between $S^{T}\left(z, y_{2}\right)$ and $S^{T}\left(z, y_{1}\right)$ on the interval $\left(R_{\max }^{T}, R_{\min }^{C}\right)$ where they are parallel. We 
can calculate $d S^{T}\left(R_{\max }^{T}\right)$ by evaluating the Bellman equation (17) at $\left(R_{2}^{T}, y_{2}\right)$ and at $\left(R_{1}^{T}, y_{1}\right)$, where $S^{T}$ is zero, then subtracting and simplifying as before. The result is

$$
(r+\rho+\lambda+\delta+\mu) d S^{T}\left(R_{\max }^{T}\right)=d y-\frac{\eta c}{1-\eta} d \theta+\lambda \int_{R^{T}} d S^{T}(z) d G(z)+O\left(d y^{2}\right)
$$

Note that the first two terms are just $\left(r+\rho+\lambda G\left(R^{P}\right)+\mu\right) d S^{P}$.

Next, consider $d S^{T}\left(R_{\max }^{C}\right)$, which is the distance between $S^{T}\left(z, y_{2}\right)$ and $S^{T}\left(z, y_{1}\right)$ on the interval $\left(R_{\max }^{C}, \infty\right)$ where they are again parallel. We can calculate $d S^{T}\left(R_{\max }^{C}\right)$ by evaluating the Bellman equation (17) at $\left(R_{\max }^{C}, y_{2}\right)$ and at $\left(R_{\max }^{C}, y_{1}\right)$, then subtracting and simplifying. The result is

$$
\left(r+\rho+\lambda+\delta+\mu_{1 \mid 2}+\mu_{2 \mid 1}\right) d S^{T}\left(R_{\max }^{C}\right)=d y-\frac{\eta c}{1-\eta} d \theta+\lambda \int_{R^{T}} d S^{T}(z) d G(z)+\delta d S^{P}+O\left(d y^{2}\right)
$$

Again, the first two terms are just $\left(r+\rho+\lambda G\left(R^{P}\right)+\mu\right) d S^{P}$.

Finally, we can calculate $d S^{T}\left(R_{\min }^{C}\right)$ by evaluating the Bellman equation (17) at $\left(R_{\min }^{C}, y_{2}\right)$ and at $\left(R_{\min }^{C}, y_{1}\right)$, then subtracting and simplifying. To simplify, we use the optimal promotion equation $S^{P}\left(R_{i}^{C}, y_{i}\right)=F /(1-\eta)$. This implies that $\operatorname{sign}\left(d R^{C}\right)=-\operatorname{sign}\left(d S^{P}\right)=\operatorname{sign}\left(d R^{P}\right)$. We obtain

$$
\left(r+\rho+\lambda+\delta+\mu_{1 \mid 2}+\mu_{2 \mid 1}\right) d S^{T}\left(R_{\min }^{C}\right)=\operatorname{sign}\left(d S^{P}\right) * \frac{\delta \eta F}{1-\eta}+O(d y)
$$

Notice that since $\left(G\left(R_{\max }^{C}\right)-G\left(R_{\min }^{C}\right)\right)$ is of order $O(d y)$, the zero-order approximation of $d S^{T}$ on $\left(R_{\min }^{C}, R_{\max }^{C}\right)$ given in (47) suffices in order to calculate the second term in (44) with an error of order $O\left(d y^{2}\right)$.

We can now use (45)-(47) to evaluate $d S^{T}$ in the three terms of (44). We obtain an equation of the form

$$
\int_{R^{T}} d S^{T}(z) d G(z)=C_{1} d S^{P}+C_{2} \operatorname{sign}\left(d S^{P}\right)+C_{3} \int_{R^{T}} d S^{T}(z) d G(z)
$$

where $C_{1}>0, C_{2}>0$, and $0<C_{3}<1$. Therefore $\operatorname{sign}\left(\int_{R^{T}} d S^{T}(z) d G(z)\right)=$ $\operatorname{sign}\left(d S^{P}\right)$.

Now finally consider what we have learned about the sign of $d S^{P}$ and the other differentials. From (43) we have $\operatorname{sign}\left(d S^{P}\right)=\operatorname{sign}\left(d y-\frac{\eta c}{1-\eta} d \theta\right)$. Thus, suppose for a moment that Assumption 5 is not satisfied. In this case, we have $0<d y<\frac{\eta c}{1-\eta} d \theta$, 
and therefore $d S^{P}<0$. From (48), we then have $\int_{R^{T}} d S^{T}(z) d G(z)<0$. But by (41), we have $\operatorname{sign}(d \theta)=\operatorname{sign}\left(\int_{R^{T}} d S^{T}(z) d G(z)\right)$. This is a contradiction.

Equilibrium therefore requires that Assumption 5 be satisfied: $\frac{\eta c}{1-\eta} d \theta<d y$. In this case, we find $\operatorname{sign}\left(d S^{P}\right)=\operatorname{sign}\left(\int_{R^{T}} d S^{T}(z) d G(z)\right)=\operatorname{sign}(d \theta)>0$, and $\operatorname{sign}\left(d R^{P}\right)=\operatorname{sign}\left(d R^{C}\right)=\operatorname{sign}\left(d R^{T}\right)<0$, as we intuitively expect.

QED.

Proof of Lemmas 3 and 6. Together, Lemmas 9 and 10 imply that the surplus functions are increasing in $z$. Lemma 11 implies that the surplus functions are increasing in $y$, as long as Assumption 5 is satisfied. Lemma 12 shows sufficient conditions under which Assumption 5 is satisfied.

QED. 
BANCO DE ESPAÑA PUBLICATIONS

\section{WORKING PAPERS ${ }^{1}$}

0901 PRAVEEN KUJAL AND JUAN RUIZ: International trade policy towards monopoly and oligopoly.

0902 CATIA BATISTA, AITOR LACUESTA AND PEDRO VICENTE: Micro evidence of the brain gain hypothesis: The case of Cape Verde.

0903 MARGARITA RUBIO: Fixed and variable-rate mortgages, business cycles and monetary policy.

0904 MARIO IZQUIERDO, AITOR LACUESTA AND RAQUEL VEGAS: Assimilation of immigrants in Spain: A longitudinal analysis.

0905 ÁNGEL ESTRADA: The mark-ups in the Spanish economy: international comparison and recent evolution.

0906 RICARDO GIMENO AND JOSÉ MANUEL MARQUÉS: Extraction of financial market expectations about inflation and interest rates from a liquid market.

0907 LAURA HOSPIDO: Job changes and individual-job specific wage dynamics.

0908 M. ${ }^{a}$ DE LOS LLANOS MATEA AND JUAN S. MORA: La evolución de la regulación del comercio minorista en España y sus implicaciones macroeconómicas.

0909 JAVIER MENCÍA AND ENRIQUE SENTANA: Multivariate location-scale mixtures of normals and mean-varianceskewness portfolio allocation.

0910 ALICIA GARCÍA-HERRERO, SERGIO GAVILÁ AND DANIEL SANTABÁRBARA: What explains the low profitability of Chinese banks?

0911 JAVIER MENCÍA: Assessing the risk-return trade-off in loans portfolios.

0912 MAXIMO CAMACHO AND GABRIEL PEREZ-QUIROS: Ñ-STING: España Short Term INdicator of Growth.

0913 RAQUEL VEGAS, ISABEL ARGIMÓN, MARTA BOTELLA AND CLARA I. GONZÁLEZ: Retirement behaviour and retirement incentives in Spain

0914 FEDERICO CINGANO, MARCO LEONARDI, JULIÁN MESSINA AND GIOVANNI PICA: The effect of employment protection legislation and financial market imperfections on investment: Evidence from a firm-level panel of EU countries.

0915 JOSÉ MANUEL CAMPA AND IGNACIO HERNANDO: Cash, access to credit, and value creation in M\&As.

0916 MARGARITA RUBIO: Housing market heterogeneity in a monetary union.

0917 MAXIMO CAMACHO, GABRIEL PEREZ-QUIROS AND HUGO RODRÍGUEZ MENDIZÁBAL: High-growth Recoveries, Inventories and the Great Moderation.

0918 KAI CHRISTOFFEL, JAMES COSTAIN, GREGORY DE WALQUE, KEITH KUESTER, TOBIAS LINZERT, STEPHEN MILLARD AND OLIVIER PIERRARD: Wage, inflation and employment dynamics with labour market matching.

0919 JESÚS VÁZQUEZ, RAMÓN MARÍA-DOLORES AND JUAN-MIGUEL LONDOÑO: On the informational role of term structure in the U.S. monetary policy rule.

0920 PALOMA LÓPEZ-GARCÍA AND SERGIO PUENTE: What makes a high-growth firm? A probit analysis using Spanish firm-level data.

0921 FABIO CANOVA, MATTEO CICCARELLI AND EVA ORTEGA: Do institutional changes affect business cycles? Evidence from Europe.

0922 GALO NUÑO: Technology, convergence and business cycles.

0923 FRANCISCO DE CASTRO AND JOSÉ LUIS FERNÁNDEZ: The relationship between public and private saving in Spain: does Ricardian equivalence hold?

0924 GONZALO FERNÁNDEZ-DE-CÓRDOBA, JAVIER J. PÉREZ AND JOSÉ L. TORRES: Public and private sector wages interactions in a general equilibrium model.

0925 ÁNGEL ESTRADA AND JOSÉ MANUEL MONTERO: R\&D investment and endogenous growth: a SVAR approach.

0926 JUANA ALEDO, FERNANDO GARCÍA-MARTÍNEZ AND JUAN M. MARÍN DIAZARAQUE: Firm-specific factors influencing the selection of accounting options provided by the IFRS: Empirical evidence from Spanish market.

0927 JAVIER ANDRÉS, SAMUEL HURTADO, EVA ORTEGA AND CARLOS THOMAS: Spain in the euro: a general equilibrium analysis.

0928 MAX GILLMAN AND ANTON NAKOV: Monetary effects on nominal oil prices.

1. Previously published Working Papers are listed in the Banco de España publications catalogue. 
0929 JAVIER MENCÍA AND ENRIQUE SENTANA: Distributional tests in multivariate dynamic models with Normal and Student $t$ innovations.

0930 JOAN PAREDES, PABLO BURRIEL, FRANCISCO DE CASTRO, DANIEL GARROTE, ESTHER GORDO AND JAVIER J. PÉREZ: Fiscal policy shocks in the euro area and the US: an empirical assessment.

0931 TERESA LEAL, DIEGO J. PEDREGAL AND JAVIER J. PÉREZ: Short-term monitoring of the Spanish Government balance with mixed-frequencies models.

0932 ANTON NAKOV AND GALO NUÑO: Oilgopoly: a general equilibrium model of the oil-macroeconomy nexus.

0933 TERESA LEAL AND JAVIER J. PÉREZ: Análisis de las desviaciones presupuestarias aplicado al caso del presupuesto del Estado.

0934 JAVIER J. PÉREZ AND A. JESÚS SÁNCHEZ: Is there a signalling role for public wages? Evidence for the euro area based on macro data.

0935 JOAN PAREDES, DIEGO J. PEDREGAL AND JAVIER J. PÉREZ: A quarterly fiscal database for the euro area based on intra-annual fiscal information.

1001 JAVIER ANDRÉS, ÓSCAR ARCE AND CARLOS THOMAS: Banking competition, collateral constraints and optimal monetary policy.

1002 CRISTINA BARCELÓ AND ERNESTO VILLANUEVA: The response of household wealth to the risk of losing the job: evidence from differences in firing costs.

1003 ALEXANDER KARAIVANOV, SONIA RUANO, JESÚS SAURINA AND ROBERT TOWNSEND: No bank, one bank, several banks: does it matter for investment?

1004 GABRIEL PEREZ-QUIROS AND HUGO RODRÍGUEZ MENDIZÁBAL: Asymmetric standing facilities: an unexploited monetary policy tool.

1005 GABRIEL JIMÉNEZ, JOSE A. LOPEZ AND JESÚS SAURINA: How does competition impact bank risk-taking?

1006 GIUSEPPE BERTOLA, AURELIJUS DABUSINSKAS, MARCO HOEBERICHTS, MARIO IZQUIERDO, CLAUDIA KWAPIL, JEREMI MONTORNÈS AND DANIEL RADOWSKI: Price, wage and employment response to shocks: evidence from the WDN Survey.

1007 JAVIER MENCÍA: Testing non-linear dependence in the Hedge Fund industry.

1008 ALFREDO MARTÍN-OLIVER: From proximity to distant banking: Spanish banks in the EMU.

1009 GALO NUÑO: Optimal research and development expenditure: a general equilibrium approach.

1010 LUIS J. ÁLVAREZ AND PABLO BURRIEL: Is a Calvo price setting model consistent with micro price data?

1011 JENS HAGENDORFF, IGNACIO HERNANDO, MARÍA J. NIETO AND LARRY D. WALL: What do premiums paid for bank M\&As reflect? The case of the European Union.

1012 DAVID DE ANTONIO LIEDO: General Equilibrium Restrictions for Dynamic Factor Models.

1013 JAMES COSTAIN, JUAN F. JIMENO AND CARLOS THOMAS: Employment fluctuations in a dual labor market.

\section{BANCODEESPAÑA}

Eurosistema
Unidad de Publicaciones

Alcalá, 522; 28027 Madrid

Teléfono +34 91338 6363. Fax +34 913386488 Correo electrónico: publicaciones@bde.es 